\title{
Modelling and Monitoring of Abrasive Finishing Processes Using Artificial Intelligence Techniques: A Review
}

\author{
Vigneashwara Pandiyan ${ }^{\mathrm{a}, \mathrm{b}}$, Sergey Shevchik ${ }^{\mathrm{b}}$, Kilian Wasmer ${ }^{\mathrm{b}}$, Sylvie Castagne ${ }^{\mathrm{c}}$, \\ Tegoeh Tjahjowidodo ${ }^{\mathrm{d}} *$ \\ a School of Mechanical and Aerospace Engineering, Nanyang Technological University, Singapore 639815 \\ ${ }^{b}$ Empa, Swiss Federal Laboratories for Materials Science \& Technology, Laboratory for Advanced Materials \\ Processing, Feuerwerkerstrasse 39, CH-3602 Thun, Switzerland \\ ${ }^{c}$ Department of Mechanical Engineering and Flanders Make@KU Leuven-MaPS, KU Leuven, Celestijnenlaan \\ 300, 3001 Leuven, Belgium \\ ${ }^{d}$ Department of Mechanical Engineering, KU Leuven, Technology campus De Nayer, Jan De Nayerlaan 5, \\ St.Katelijine- Waver, Belgium
}

* Corresponding author. Tel.: +32 15688143; E-mail address: tegoeh.tjahjowidodo@kuleuven.be

\begin{abstract}
Abrasive finishing processes such as grinding, lapping or disc polishing are one of the most practical means for processing materials to manufacture products with fine surface finish, surface quality and dimensional accuracy. However, they are one of the most difficult and least-understood processes for two main reasons. Firstly, the abrasive grains present in the tool surface are randomly oriented. Secondly, they undergo complex interactions in the machining zone. Given the advances in sensor technologies, the finishing processes can now be sensorized, and the vast amount of data produced can be exploited to model and monitor the processes using Artificial Intelligence techniques. Data-driven models have turned into a hot focus in engineering with the rise of machine learning and deep learning algorithms, which have greatly spread all through the academic community. The scope of this paper is mainly to review the application of Artificial Intelligence as well as supporting sensing and signal processing techniques in modelling and monitoring on different types of abrasive processes in metal finishing. The paper gives a detailed background on the key mechanisms and defects in the different abrasive finishing process and lists the suitable sensing techniques for their monitoring. The paper reports that most of the Artificial Intelligence algorithms available are not fully exploited for monitoring and modelling in abrasive finishing and emphasizes on bridging this gap. The probable research tendency on datadriven monitoring and modelling for abrasive finishing is also forecasted.
\end{abstract}

Keywords: Abrasive Machining; Machine Learning; In-situ Monitoring; Sensors; Signal Processing; Grinding

\section{Introduction}

The development of newer materials and the necessity of adhering to quality output have always driven research areas in modelling and monitoring of abrasive finishing processes. In many finishing processes, the use of advanced materials to meet different requirements in an industrial scale will only be possible if they can be machined economically. The process dependent behaviour of the surface quality, material removal and tool wear mechanism besides the numerous uncontrollable variables can be modelled, optimized and monitored upfront in abrasive processes by identifying the patterns in the data (either sensor or process inputs) using Machine Learning (ML) especially Deep Learning (DL) algorithms. This work reviews the most relevant aspects from previous research works presented in the literature on modelling and intelligent monitoring of finishing processes on metals using Artificial Intelligence (AI) algorithms. The paper highlights the progress made in this area and discusses the issues that need to be addressed. The paper is organized in the following: The scope of the article and its structure is introduced in Abstract and Section 1. Basic AI concepts are introduced and discussed mainly in the context of application to machine intelligence and machining in Section 2. A brief overview of the manufacturing process, followed by a brief outline of abrasive finishing processes is presented in Section 3. Section 3 reports the critical variables that are to be modelled and discrete events that are to be monitored in finishing processes. Sensing technologies capable of monitoring finishing processes are listed in Section 4. This section is followed by research efforts in modelling and monitoring finishing process using AI techniques in Section 5. Finally, in Section 6, guidelines or key issues for the development of new intelligent machining systems in finishing processes are presented as the conclusions.

\section{Overview of Artificial Intelligence in Manufacturing}

Manufacturers require an ability to enhance the quality of machining processes to meet tight tolerances by careful monitoring and modelling. The capability to model and monitor the process inputs and outputs, in 
turns, will allow the system to compensate for any possible process faults to guarantee the output quality and increase productivity. Quality output and increased productivity have been two of the biggest reasons for the integration of machine intelligence in the production line [1]. Complete automation using machine intelligence can be fully accomplished in any machining process when computers learn from the process. Implementation of machine intelligence for modelling and monitoring requires various sensors and process variables as inputs and an $\mathrm{AI}$ technique trained on these data for a specific objective. The AI techniques are the set of Machine Learning (ML) and Deep Learning (DL) algorithms which have embedded mathematical representation of the objective to be achieved [2]. Fig. 1 shows all elements, required for accomplishing machine intelligence and the essential element is AI algorithms for decision making. Suitable signal processing and a correct choice of ML and DL algorithms are required in most of cases if the information from sensor signals is to be used for monitoring purposes. Integration of manufacturing processes with AI will provide them with self-monitoring and decision-making capabilities which redefines them.

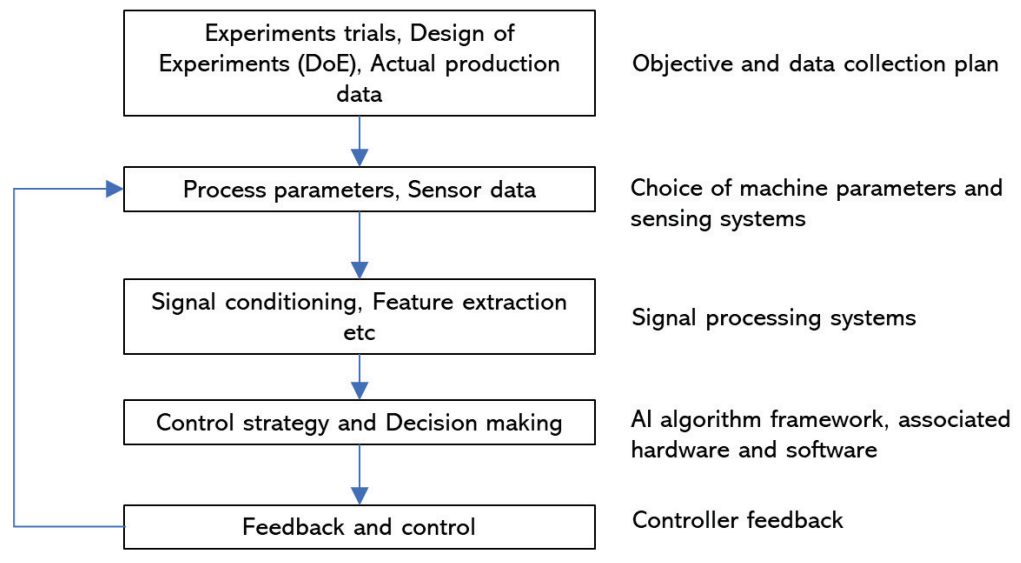

Fig. 1 Building blocks to achieve machine intelligence.

Monitoring methods using thresholding techniques on sensor data in machining processes aides to identify simpler phenomena such as tool breakage etc. in real-time from the process [3, 4]. Thresholding techniques work better when the signal pattern changes drastically and is easily noticeable. However, for a complex mechanism such as progressive tool wear, the sensor data appears highly non-linear, and thresholding techniques fail [5]. Decoding of such patterns in the sensor data to corresponding mechanisms requires ML and DL algorithms. ML and DL algorithms can detect arrangements of the high-dimensional data space yielding information about a given system or data set. Several ML algorithms, such as Artificial Neural Networks (ANN), Fuzzy Inference Systems (FIS) and techniques based on hybridization of these two techniques called neuro-fuzzy inference systems have been widely used in the past for modelling and monitoring machining systems [6]. In the past, for monitoring the conditions of machining state, ANN has frequently been used followed by fuzzy sets [6]. Among the enormous number of AI approaches that have been created in the past, the characteristics of most commonly used ones in the manufacturing domain are summarized in Table 1.

Table 1. Characteristics of ML and DL algorithms commonly used in manufacturing.

\begin{tabular}{c|l}
\hline Technique & \multicolumn{1}{c}{ Characteristics } \\
\hline \multirow{3}{*}{$\begin{array}{l}\text { Artificial neural } \\
\text { network (ANN) }\end{array}$} & $\begin{array}{l}\text { ANN's are a class of algorithms that imitate the architecture of neuron inter- } \\
\text { connection in the human brain. A typical ANN architecture consists of three layers, } \\
\text { namely input, hidden and output. The choice of neuron numbers in each layer depends } \\
\text { on factors such as input/output parameters, dataset distribution, and presentation } \\
\text { format of the dataset to the network. The ability of the network primarily depends on } \\
\text { the layered architecture, activation and loss function. During training, ANN's map } \\
\text { points in the input space to output space by modifying the weight component in the } \\
\text { connections between neurons. The effectiveness of ANN modelling based on } \\
\text { approaches such as backpropagation neural network and feedforward neural network } \\
\text { for predicting surface roughness has been proved in hard cutting[7-9]. ANN is } \\
\text { generally used when the knowledge of the process is unknown. ANN is known for its } \\
\text { accuracy and also for its excellent generalization capability. Nonetheless, they possess } \\
\text { an in-built disadvantage as the interpretation of knowledge acquired and the patterns } \\
\text { recognized by each node within them requires extra work, and it behaves like a black- }\end{array}$ \\
\hline
\end{tabular}




\begin{tabular}{|c|c|}
\hline & box model. \\
\hline $\begin{array}{l}\text { Fuzzy Inference } \\
\text { Systems (FIS) and } \\
\text { Adaptive Neuro- } \\
\text { Fuzzy Inference } \\
\text { Systems (ANFIS) }\end{array}$ & $\begin{array}{l}\text { Compared to ANN, there are a lesser number of applications of fuzzy sets for the } \\
\text { prediction of machining performance from literature. FIS is applied when there are } \\
\text { enough knowledge and understanding of the process [10]. The advantage of the fuzzy } \\
\text { sets over ANN's is that the acquired knowledge could be extracted and implemented } \\
\text { as a set of if-then rules with membership function such as sigmoid, triangular etc. [11]. } \\
\text { Though, human knowledge could be transferred to the model, the methods of } \\
\text { transferring to the model are insufficient. To take the advantages of both ANN and } \\
\text { FIS, a hybrid technique called neuro-fuzzy systems were introduced. A typical neuro- } \\
\text { fuzzy system eradicates the fundamental problem in fuzzy if-then rules by exploiting } \\
\text { the learning competence of an ANN for automated optimization of fuzzy if-then rules } \\
\text { during training. A significant advantage of such a hybrid approach is that the } \\
\text { knowledge of the model could be obtained from ANN, which was not possible when it } \\
\text { was used standalone [12]. }\end{array}$ \\
\hline $\begin{array}{l}\text { Support vector } \\
\text { machines (SVM) }\end{array}$ & $\begin{array}{l}\text { The SVM is a collection of ML algorithm that is state of the art in the separation of } \\
\text { nonlinear data [13]. They solve nonlinear problems by applying a kernel function trick. } \\
\text { The data is mapped onto a high-dimensional feature space where the linear } \\
\text { formulation can be derived from the non-linear form by indirectly mapping feature } \\
\text { space and finally train them. The SVM's possess properties such as generalization } \\
\text { ability, free adjusting parameters, and no requirement for experimentation to find the } \\
\text { learning machine architecture, which enables to solve highly nonlinear problems with } \\
\text { ease [14]. They are used extensively in the classification of tool-wear[15, 16] and } \\
\text { estimation of material removal [17] for machining processes. }\end{array}$ \\
\hline $\begin{array}{l}\text { Decision Trees } \\
\text { (DT) and Random } \\
\text { Forest (RF) }\end{array}$ & $\begin{array}{l}\text { DT's learn from data space to approximate the output with a rule base consisting of if- } \\
\text { then-else conditions. They are a bit prone to overfitting and are seldom used in } \\
\text { modelling machining processes. However, their actual power can be realized when } \\
\text { multiple DT's join together to form RF. The RF's operate by constructing a multitude } \\
\text { of DT's. One of the most significant advantages of RF over DT is that the algorithm } \\
\text { works on bootstrapping [18]. RF creates a lot of individual DT's by re-sampling the } \\
\text { data many times with replacement and makes the final prediction at a new point by } \\
\text { averaging the predictions from all the individual DT's on this point. Averaging over all } \\
\text { DT's results in a reduction of variance, thereby, enhancing the accuracy of the } \\
\text { prediction. }\end{array}$ \\
\hline $\begin{array}{l}\text { Convolutional } \\
\text { Neural Networks } \\
(\mathrm{CNN})\end{array}$ & $\begin{array}{l}\text { CNN is just one kind of state-of-the-art ANN wherein the network architecture is more } \\
\text { in-depth with embedded convolution. The fundamental design principle of CNN is } \\
\text { tailoring the architecture and learning algorithm in such a way that it reduces the } \\
\text { number of the free parameter without compromising the computational power of } \\
\text { learning algorithm [19]. The typical architecture of CNN consists of several layers. } \\
\text { There are convolutional layers, pooling layers and fully connected dense layers [20]. } \\
\text { The model accuracy depends dramatically on the influence of the selection of a set of } \\
\text { hyperparameters [21]. Unlike ML, CNN's can be fed with raw data values rather than } \\
\text { feature vectors [22] as input, as shown in Fig. } 2 \text { The convolution processes act as } \\
\text { appropriate feature detectors that demonstrate the ability to deal with a large amount of } \\
\text { low-level information. Since CNN's possess a lot of layers in its architecture and learn } \\
\text { the representation of the data space during training, they are grouped as DL. With the } \\
\text { ability to learn features from raw data, DL has also become a promising tool for } \\
\text { modelling and monitoring machining processes [23,24]. }\end{array}$ \\
\hline
\end{tabular}

Apart from these ML techniques, some efforts have been made to predict machine and machining status using Hidden Markov Models (HMM's) [25, 26], Genetic Algorithms (GA) [27, 28] and Naïve Bayes [29, 30]. The choice of ML techniques depends primarily on previous knowledge of the process; sensor signals data features, experimental objective, the experimental data set and, last but not least, the level of accuracy required for industrial implementation. Most of the ML techniques require input information as statically features during 
training, as shown in Fig.2. Comparisons of DL methods with traditional ML methods using time, frequency and wavelet features suggest that DL methods also have a similar ability to characterize the signal for cutting states monitoring [31]. Martínez-Arellano et al. [32] have transformed the time-series signal to an image and applied a CNN to classify flank wear. Similarly, CNN's were involved for in-situ and real-time quality monitoring using AE to classify the qualities of parts during Additive Manufacturing (AM) [33]. The AI tools discussed in this section are sufficed in building intelligent systems for modelling and monitoring of machining processes. Apart from accuracy, it is to be noted that the computational time plays a significant role in the choice of AI algorithms or soft computing techniques. Having proper model knowledge of the system and successful integration of the system with process monitoring, and accurate decision-making capabilities will help industries to increase productivity, quality, safety and profitability.

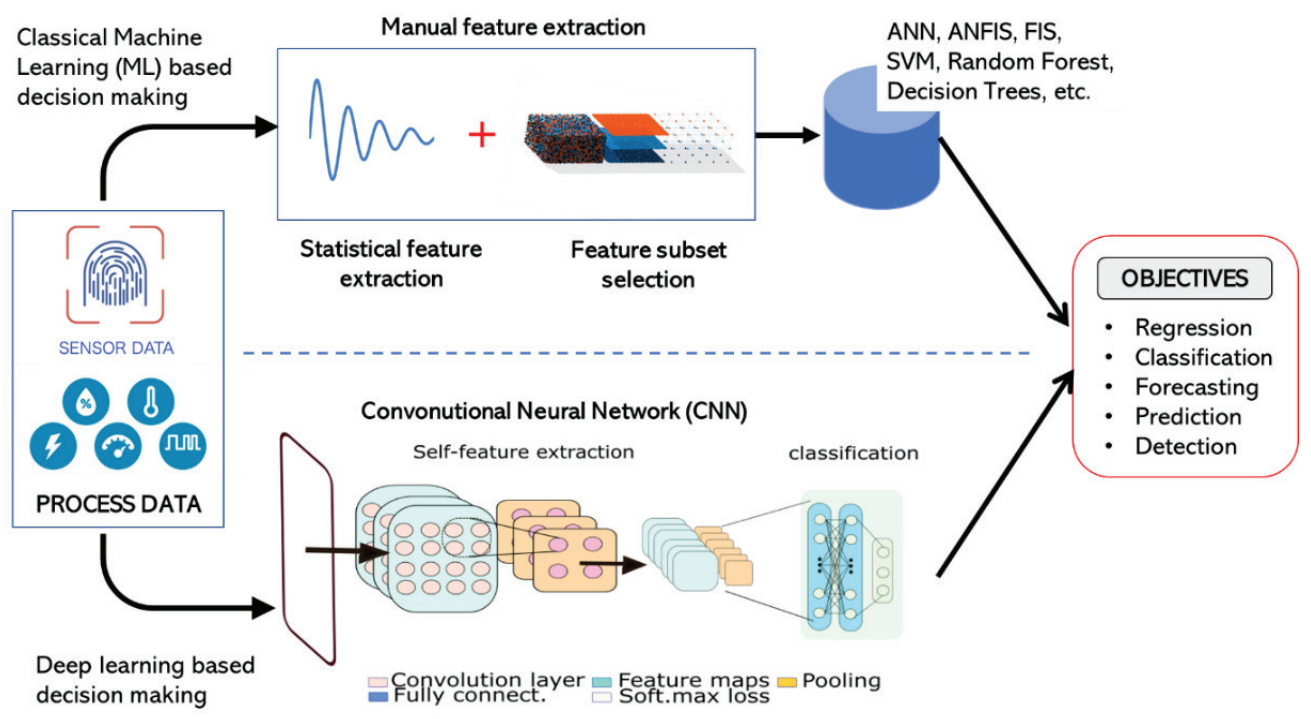

Fig.2 Comparison between traditional machine learning and convolutional neural network.

\section{Review on Abrasive Systems}

In the previous section, it was mentioned that the AI algorithms depend on many factors including the process. Hence, even though this contribution reviews the modelling and monitoring of abrasive processes using AI, it is important to review the different abrasive systems.

Manufacturing involves the transformation of the material from its initial geometry and property to the desired shape. The manufacturing processes are classified into primary and secondary processes [34]. The primary processes comprise extruding, casting, forming and forging of the material [34]. Primary manufacturing processes are much useful to give a fundamental property, shape, and size so that materials can be further processed by secondary processes. The components produced from the primary process are then machined to the required size, shape, tolerance, surface quality during secondary manufacturing processes. The secondary processes maintain the surface quality and form accuracy required as per design specifications [35]. Traditionally, secondary manufacturing involves machining processes such as milling, turning or broaching that use cutting tool inserts. A new form of secondary processes, such as abrasive machining, is now on the rise as the traditional secondary processes have lower repeatability and lower accuracy. Though abrasive machining processes are costly, they can achieve finer surface quality than traditional machining processes [36, 37]. The process of abrasive machining works similarly to traditional machining as the abrasive grain acts as the cutting tool insert, as shown in Fig.3. Machining processes which use abrasives to remove material are otherwise called finishing or polishing. 


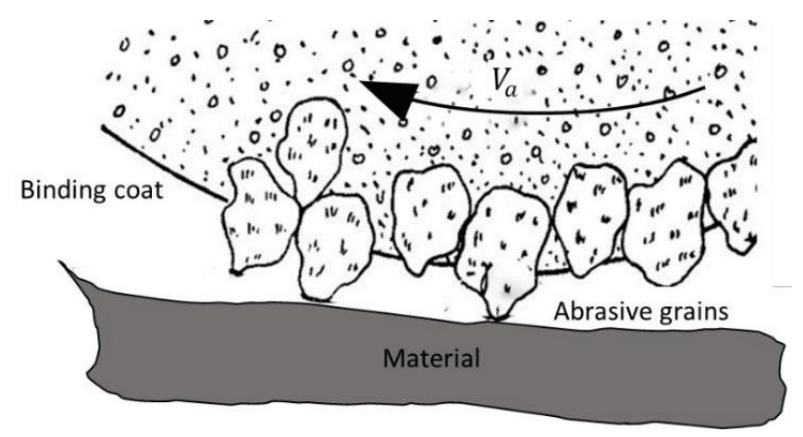

Fig.3 Principle of abrasive machining process.

The difference between a cutting tool and abrasive grains is that the grains have undefined geometry and are distributed randomly with different orientation. Abrasive machining technique has multiple benefits over the traditional secondary manufacturing processes [38]. The tool radius of the traditional secondary processes is larger than that of an abrasive grain, which is in order of microns. As a result, they generate higher internal stress and Heat Affected Zone (HAZ). Conversely, in the case of abrasive processes, extremely thin chips are produced, which ensures that the machining stress concentrates at very local points. This results in higher specific energy at machining zone for abrasive machining processes enabling them to machine hard materials $[39,40]$. Furthermore, the likelihood for the traditional machining tools to encounter a void or micro level defect is very high as metals are non-homogenous at the micro level. This results in the creation of microcracks that propagate to the next void giving rise to a discontinuity in chip formation and uneven surface.

In abrasive machining, material removal occurs due to the interaction of randomly oriented multipoint grain tips on the workpiece material. This random interaction results in a fraction of the material to be removed. As the grains or abrasives become dull, the cutting forces increase. The increase in the cutting force causes the grains to plough and rub rather than cut. As the ploughing and rubbing increases, the grains fracture at the cutting edge to reveal a new cutting edge. Self-sharpening and regeneration of the abrasive tools are also crucial advantages in abrasive machining as compared to traditional tools that are subjected to wear [37]. Unlike other machining processes, the failure of one cutting edge does not affect the process. The abrasive processes are consequently quite stable.

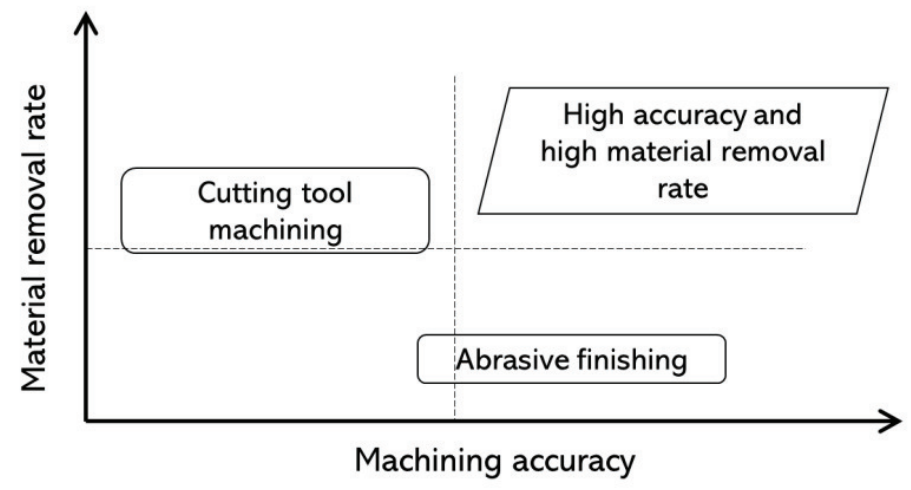

Fig.4 Application fields of Abrasive machining and cutting-tool machining. Reprinted by permission from Elsevier License: Elsevier [37].

An abrasive particle is a hard mineral that occurs naturally such as crystalline silicon carbide ( $\mathrm{SiC}$ ), aluminum oxide $\left(\mathrm{Al}_{2} \mathrm{O}_{3}\right)$ or artificially made one such as cubic boron nitride (CBN) [41]. These abrasives grains are formed into different tools for finishing operations by using a binder or by coating on top of backing material or by imparting kinetic energy. As the abrasive grains have a negative rake angle of different values and orientation, these tooltips are considered as undefined cutting edges. Due to this undefined tooltip and negative rake angle, the specific energy is very high at the machining point [39, 40]. All abrasive finishing processes are intended to generate surfaces for defined tolerance as per design quality [42]. Based on the interaction of the abrasive grains on the workpiece surface, abrasive machining is classified into two-body and three-body abrasive processes [43], which are schematically presented in Fig.5a and 3b, respectively. 


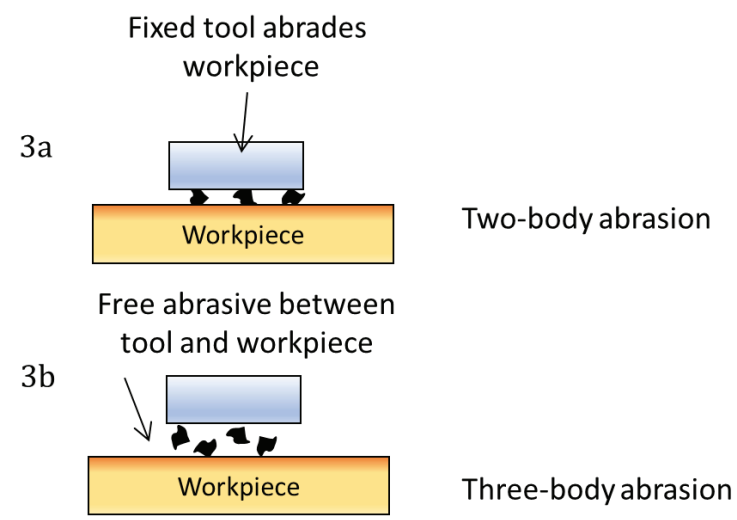

Fig.5 Illustration of two-body and three-body abrasive interaction.

Two-body abrasive processes can be further classified into two categories, namely bonded abrasive and coated abrasive processes. Bonded abrasive processes have a rigid abrasive tool of different shapes which are mixtures of grains, fillers, and adhesive bonds. In bonded abrasives, the grain particles are bound together within a matrix, and their combined shape determines the geometry of the finished workpiece. Coated abrasive processes use tools that are made of abrasive grain bound by adhesive films to a backing material such as resin, paper, cloth, rubber. Coated abrasive tools are characterized by three main properties, namely grain particles, adhesives, and backing. Grinding and honing are two common examples of bonded abrasive tools, while the examples of those classified as coated abrasive tools are belts, discs and flap wheels. [44]. An advantage of coated abrasives over other types of abrasive cutting tools is attributed to their compliance as they conform to the surface shape of the workpiece regardless of complexities, giving rise to higher quality surface finishes as illustrated in Fig.6. In Fig.5b, three body abrasive machining processes polish the surfaces by action of free or loose abrasive interactions. As the name suggests, the abrasives are free and not bound within a matrix. The process could be with or without lubrication. The abrasives could be dry or in the form of a slurry. These abrasive grains move freely over the machining surface.

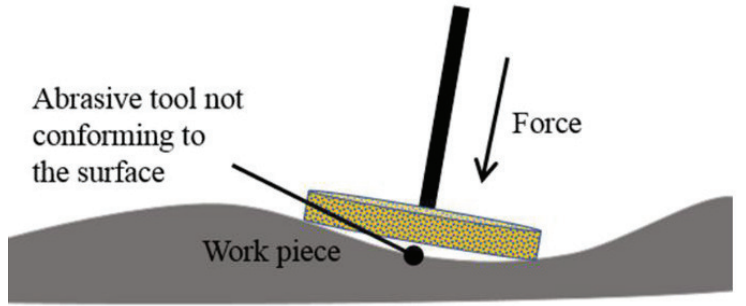

Rigid abrasive tool

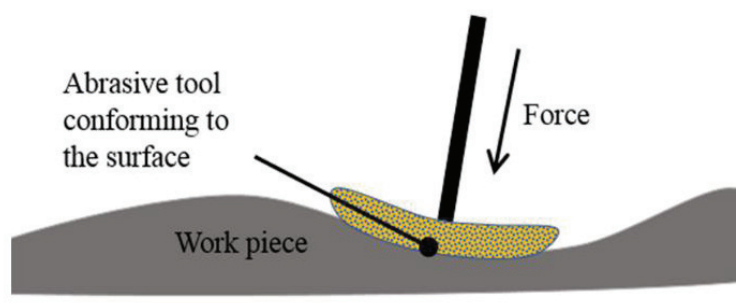

Compliant abrasive tool

Fig.6 Comparison of contact characteristics of rigid bonded and coated compliant tools. Reprinted by permission from Elsevier License: Elsevier [45].

From an energy point of view, three body interaction is a less efficient process since each collision leads to energy dissipation, whereas in two body interaction, the energy is completely transferred. However, as the new cutting edges are present during the three body interaction process, the surface quality increases at a high rate. Two body interaction can cut much more in-depth than three body abrasion because the grains are held rigidly. The mapping of the abrasive processes is illustrated in Fig.7. 


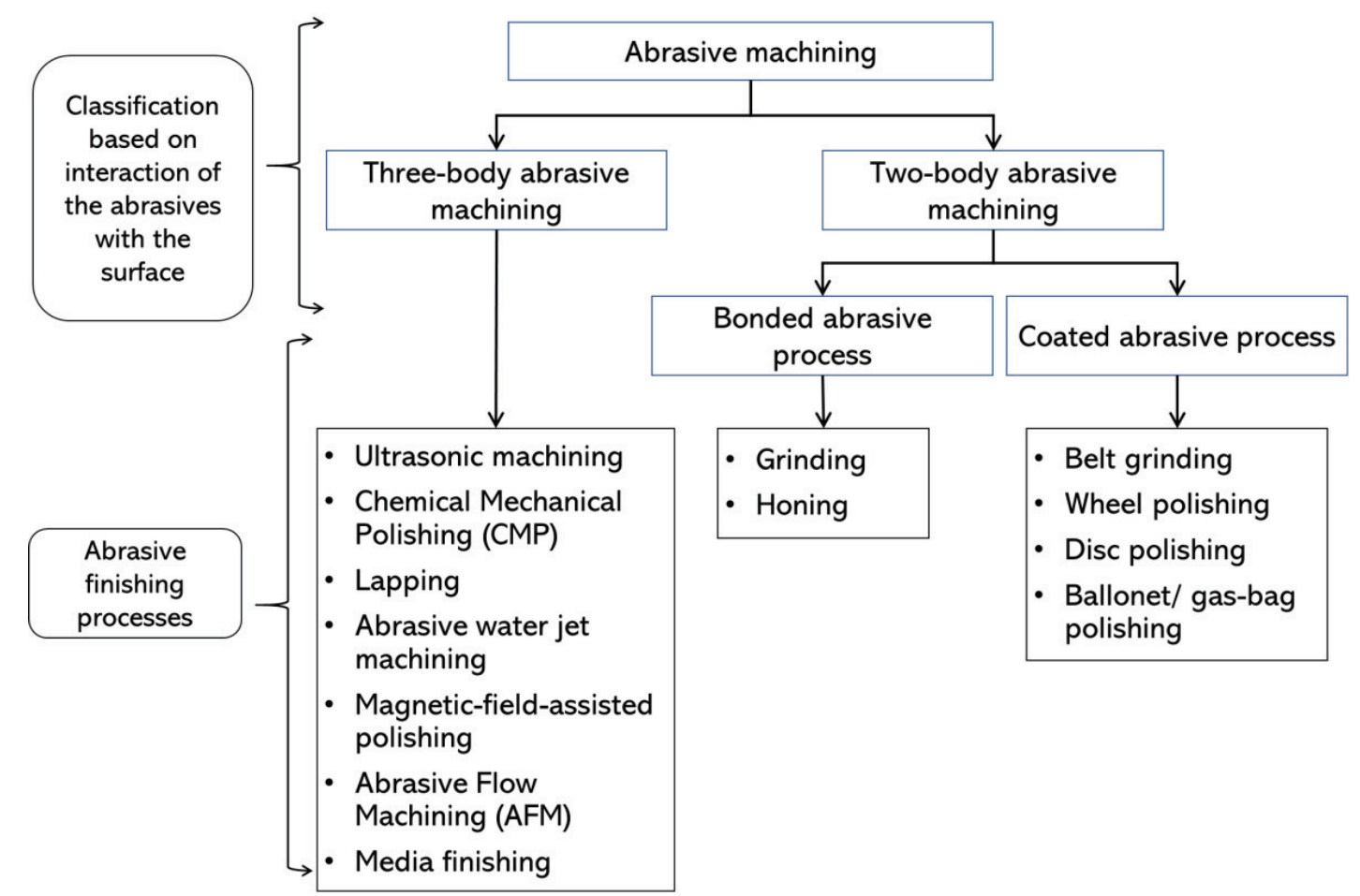

Fig.7 Classification of abrasive process based on abrasive interaction.

Grit geometry may undergo substantial change due to mechanical or chemical attrition leading to rounding or flattening of the sharp cutting points[46, 47]. Chip material adhered to the tip of the grit because of some chemical affinity can also change the effective rake angle of the grit leading to high force, temperature and poor performance of the abrasive processes. Grit with favorable geometry can produce chip in shear mode. On the other hand, grits having sizeable negative rake angle or rounded cutting edge do not form chips but may rub or make a groove by ploughing leading to the lateral flow of the workpiece material. Many aspects of interactions between cutting tool, workpiece, and material removal during abrasive processes are not fully understood due to high multiple cutting edges.

\subsection{Material removal mechanisms}

The abrasive finishing process is a track-bound undefined tool engagement, where the forefront of the grain penetrates the workpiece along a pathway and, after a phase of elastic deformation, plastic flow of the workpiece material occurs. In abrasive processes, each abrasive grain particle removes a tiny bit of material when it forces onto the surface of the workpiece. The material removal performance of the abrasive grains is significantly influenced by the material property, as shown in Fig.8. The contact area of the grain on the surface is determined by the hardness property of the material [48]. The suitability of abrasive materials to grind workpiece materials efficiently depends on their attritious wear resistance. The abrasive should be harder than the workpiece material being ground. 


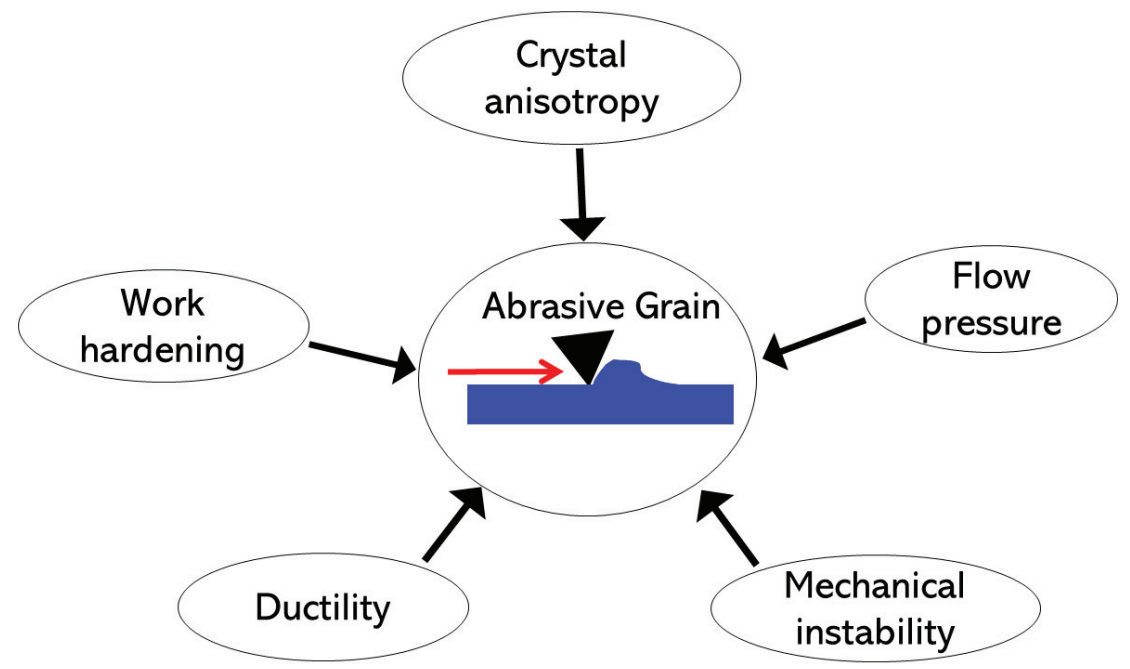

Fig. 8 Properties of materials that influence abrasive wear. Reprinted by permission from Elsevier License: Elsevier [48].

Many events occur in the interaction zone of the grain and work coupon, as shown in the Fig.9. Chipping and cracking of grains happen when they exceed the fatigue resistance of the material. The grains also dislodge out of the bond bridges also as a result of exceeding fatigue resistance. Monitoring the state of the abrasive layer in contact with the workpiece can be useful for an indirect determination of the quality of the surface generated. Out of the various events occurring in the interaction zone, only three events namely rubbing, ploughing and cutting are significantly responsible for the modification of the surface, i.e., material removal or surface wear in abrasive finishing process [49-52]. Rubbing is typically characterized by the interaction between both the abrasive grain and the material without any plastic deformation on the surface. Ploughing is often considered to have negligible wear on the surface as it creates a continuous groove with ridges on both sides resulting in dislocations rather than removal due to plastic deformation. Cutting is the actual material removal process as the cutting tool tip with sufficient force enters deeply into the workpiece causing chip formation. The cutting and ploughing phenomena from single-point scratch tests are represented in Fig.10.

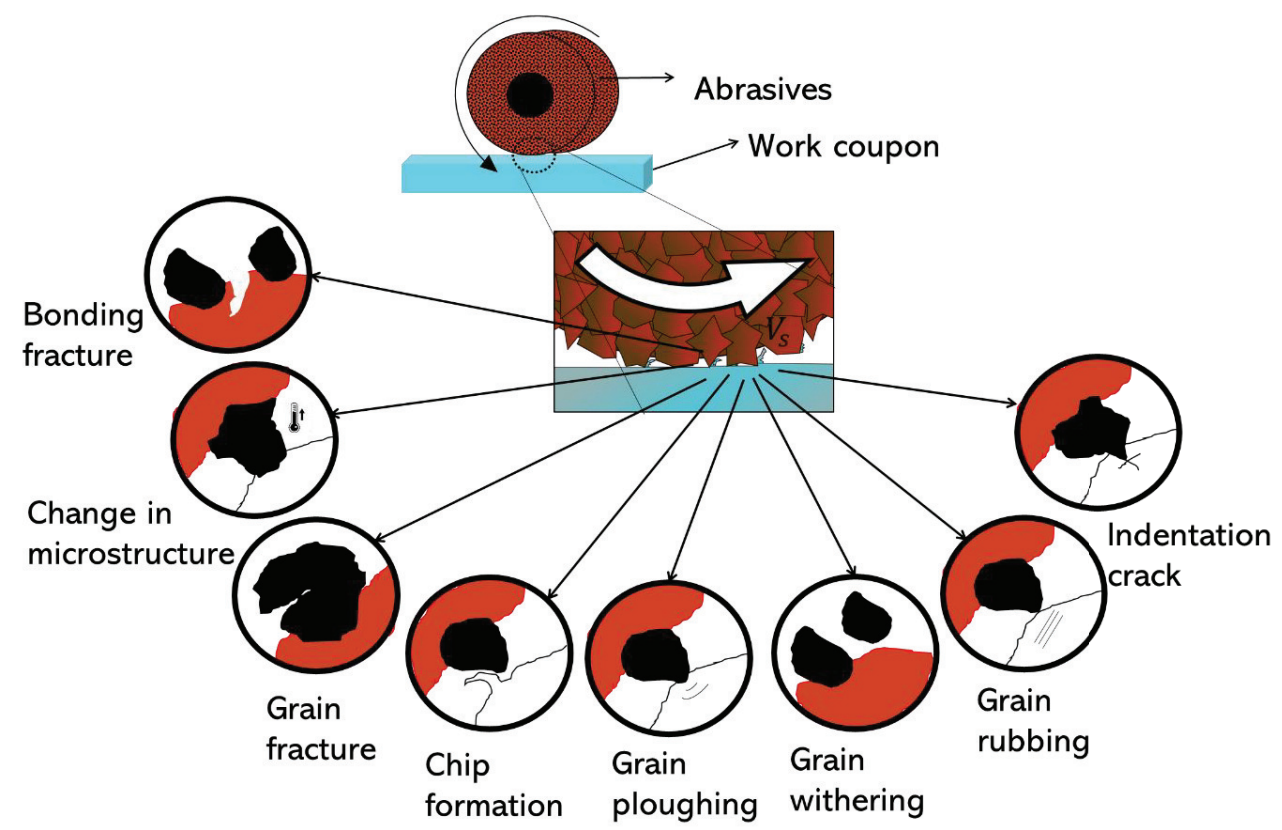

Fig.9 Various events occurring in the grinding zone. Reprinted by permission from Elsevier License: Elsevier [45]. 

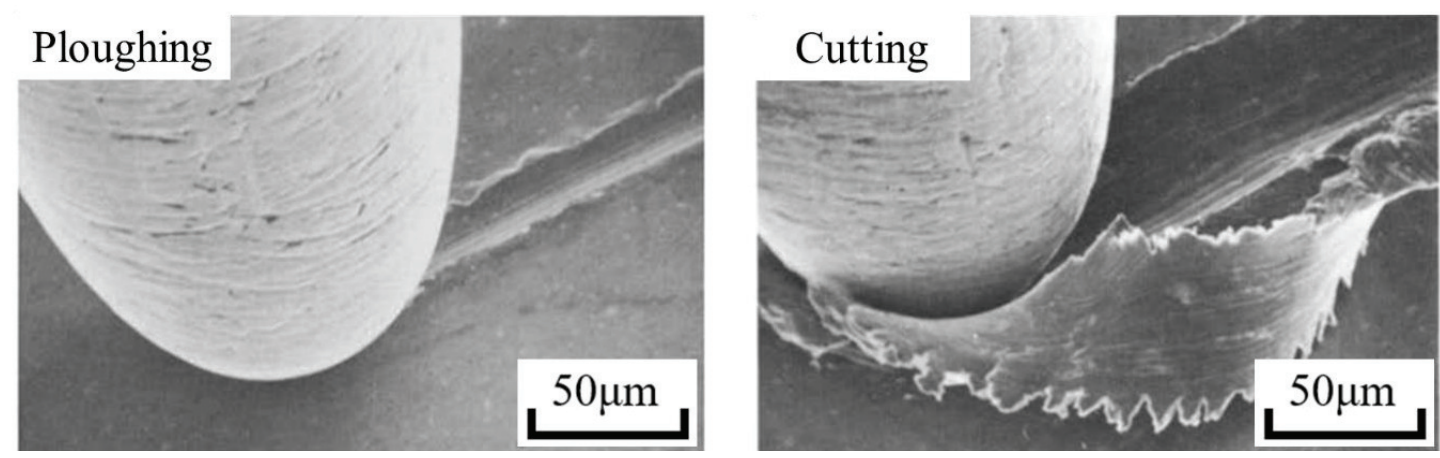

Fig.10 Scanning electron microscope (SEM) image depiction of ploughing and cutting on workpiece surface.

Reprinted by permission from Elsevier License: Elsevier [53].

Studies on the interaction between the abrasive particle and workpiece material revealed that abrasive machining exhibits different types of surface wears [54] as shown in the Fig.11. For finishing processes, the surface wear mechanism can be categorized into micro-ploughing, micro-cutting, micro-cracking and microfatigue as shown in the Fig.11. Micro-ploughing results in the displacement of the material, unlike microcutting, where the material is detached from the surface. Micro-fatigue is the removal of material from the surface due to cyclic displacement as a result of micro-ploughing. Micro-cracking is a phenomenon of material removal where the material is detached by the propagation of cracks and stress concentration. Micro-cutting is the dominant processes on ductile materials while micro-cracking is predominant in brittle materials.

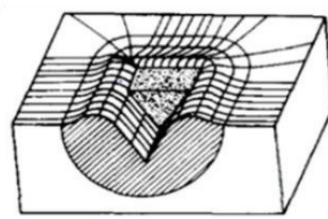

Micro-ploughing

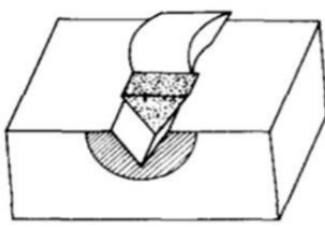

Micro-cutting

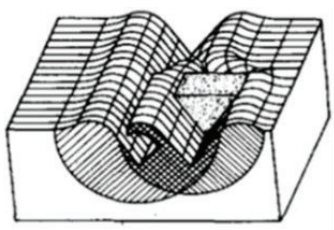

Micro-fatigue

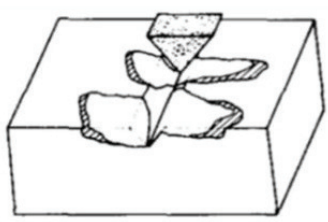

Micro-cracking

Fig.11 Surface wears generated from abrasive machining processes. Reprinted by permission from Elsevier License: Elsevier [54].

\subsection{Surface and sub-surface properties}

Every machining job leaves behind characteristic marks on the machined surface, commonly known as surface roughness. Surface roughness is one of the essential quality aspects that determines the result of the finishing process on the workpiece. In addition, contact forces, deformations and heat generated during the abrasive process are also responsible for microstructural changes in the sub-surface of the material. Most recently, there is an increase in attention on also verifying the surface integrity as illustrated Fig.12, especially if it is a functional surface [55]. The quality of the surface integrity is measured based on the values of hardness and residual stresses in the ground workpiece.

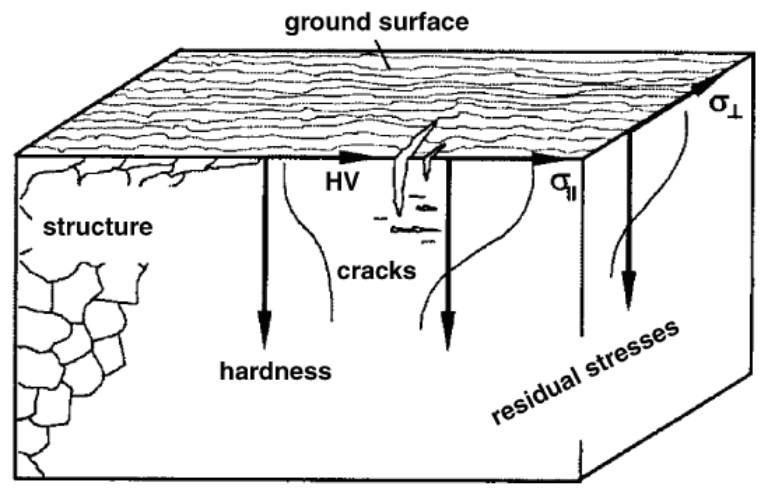

Fig.12 Ground-surface integrity. Reprinted by permission from Elsevier License: Elsevier [56]. 
Surface integrity refers to the characteristics of the surface and sub-surface, which include hardness, residual stresses, micro-cracks, grain refinement and phase transformations [57-59]. Those process outputs will be strongly influenced by the type of abrasive process selected and its input parameters. In particular, whether the process can be classified as mechanical (i.e. plastic deformation such as in belt finishing [60]) or thermomechanical (i.e. temperature rise associated with plastic deformation such as in grinding [61]), will affect the transformations occurring at the surface and sub-surface and consequently the surface integrity.

The quality of the surface is commonly evaluated based on the values of hardness and residual stresses in the ground workpiece. Processes can also be tailored to combine the beneficial effects of two techniques such as in grind-hardening where localized heating generated by the grinding process is used in a controlled manner to harden the surface of the workpiece [62]. Another example is the generation of compressive sub-surface residual stresses during abrasive flow machining [63] to improve the fatigue life of the component. In order to produce a surface with the required surface integrity, it is then important to monitor and control the process parameters that influence residual stresses and hardness.

\subsection{Influence and selection of the tool}

The importance of the grit shape, i.e. geometry of abrasive particles can be easily realized because it determines the grit geometry, e.g. rake and clearance angle, which in turn dictates the surface quality. With cycle time, there is a gradual deterioration of grains, leading to the creation of wear surfaces. Though the grains are regenerative in bonded abrasive tools, their form and geometry get changed, which has to be sensed and compensated. The grain/bond breakdown modes that are commonly found in abrasive tools are illustrated in Fig.13.

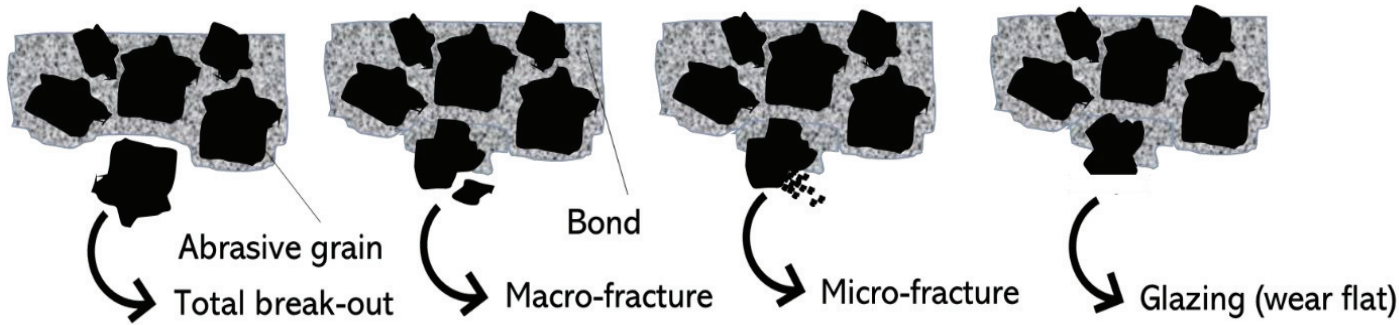

Fig.13 Grain/bond break down modes common in abrasive processes [64], with kind permission from Springer Science.
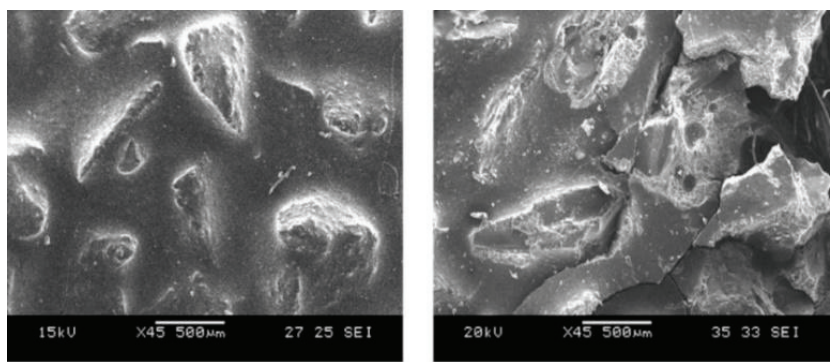

SEM image of coated abrasive new and old belt tool

Fig.14 Scanning electron microscope (SEM) image of coated abrasive new and old belt tool.

Industrial interest in tool condition monitoring for coated abrasives has significantly augmented in recent years as unlike other rigid abrasive machining tools the grains are not regenerated. Fig. 14 shows the Scanning Electron Microscope (SEM) image of a new and old abrasive belt tool. In the old coated abrasive tool, we can see deformations that will severely affect the surface's quality. As the coated abrasive tool is being worn down, the edge geometry of abrasive grains is modified continuously. The selection of finishing/polishing process depends upon various parameters such as initial and final surface, the geometry of the workpiece, finishing time, cost of the tool, complexity involved in machine setup, etc. [65].

Table 2 Choice of abrasive tools for different finishing operations.

\begin{tabular}{|c|c|c|c|}
\hline Consideration & Rigid abrasive tool & Compliant abrasive tool & Loose abrasive tool \\
\hline Faster finishing time & $\checkmark$ & $\checkmark$ & $\times$ \\
\hline
\end{tabular}




\begin{tabular}{|c|c|c|c|}
\hline Fine surface roughness & $\checkmark$ & $\checkmark$ & $\checkmark$ \\
\hline Deburring edges & $\checkmark$ & $\checkmark$ & $\checkmark$ \\
\hline $\begin{array}{l}\text { Finishing internal } \\
\text { channels }\end{array}$ & $\times$ & $\times$ & $\checkmark$ \\
\hline $\begin{array}{l}\text { Finishing intricate } \\
\text { geometries }\end{array}$ & $\times$ & $\checkmark$ & $\checkmark$ \\
\hline Process cost & $\times$ & $x$ & $x$ \\
\hline More prone to tool wear & $x$ & $\checkmark$ & $x$ \\
\hline Material removal rate & $\checkmark$ & $\checkmark$ & $x$ \\
\hline Use of coolant & $\checkmark$ & $\checkmark$ & $\times$ \\
\hline Hand-held & $\checkmark$ & $\checkmark$ & $\times$ \\
\hline \multicolumn{4}{|c|}{$\sqrt{ } \mathrm{Ok} \times \operatorname{Not} \mathrm{OK}$} \\
\hline
\end{tabular}

Most often the selection of abrasive finishing processes primarily depends on the geometry of the surface and can be grouped into three categories based on tooling, namely rigid abrasive, compliant abrasive and loose abrasive tools. Finishing of three-dimensional (3D) surfaces such as grooves, projections, or complex, indepth profiles is a trivial task for many abrasive finishing processes. For surface finishing and stock removal of complicated geometries such as turbine blades, compliant abrasive tools are suitable contenders as compared to rigid abrasive tools and loose abrasive tools [66]. In case of deburring edges, compliant tools in the form of flap discs/wheel, as well as three-body abrasive tooling such as media finishing, are suitable options. Rigid tools such as cylindrical grinders are often used for finishing cylindrical surfaces, flats surfaces, etc. Table 2 shows the choice of abrasive tools for different finishing conditions. The most common problems faced by the industries after adopting the three tooling types of finishing operations are discussed in Sections 3.4, 3.5 and 3.6.

\subsection{Rigid abrasive tools}

Grinding and honing are processes which employ rigid abrasive tools. The rigidity is due to the binder that holds all abrasive grains. In grinding, the abrasive tool is generally in the form of a wheel and, nowadays, we have grinding tools with different geometries (mounted points) to cater to different finishing operations as shown in the Fig.15. Honing is an abrasive method for processing inner, cylindrical surfaces and is commonly used in texturing of cylinder liners [67]. Tools geometry and property of both grinding and honing are more or less the same with a difference in the cutting motion were one component is a stroke motion.

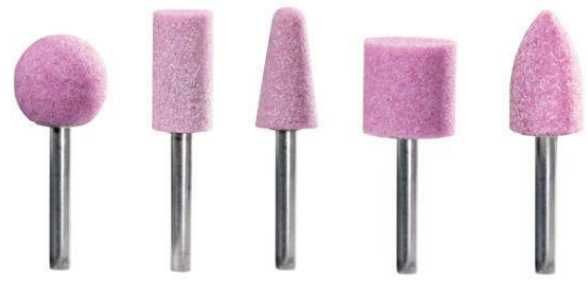

Fig.15 Grinding tool with different geometry (mounted points).

The interaction between the workpiece and the surface of the grinding tool defines the grinding process. During the grinding process, the tool is subjected to mechanical, thermal and chemical loads. As a result, the macro and micro-geometry of the tool get affected. The macro geometry effects correspond to the wear of shape, profile and geometry of the tool as illustrated in Fig.16 and micro-geometry effects correspond to the wear of granularity of the abrasives embedded. Wear of shape, profile and geometry in rotating grinding tools can cause eccentricity, form or structure errors on the work coupon. Wear profile of rigid grinding tools are caused by the feed direction. The chatter vibrations that arise from the dynamic behavior of the machine can also deteriorate macro geometry, and the profile of the surface machined [68,69]. 

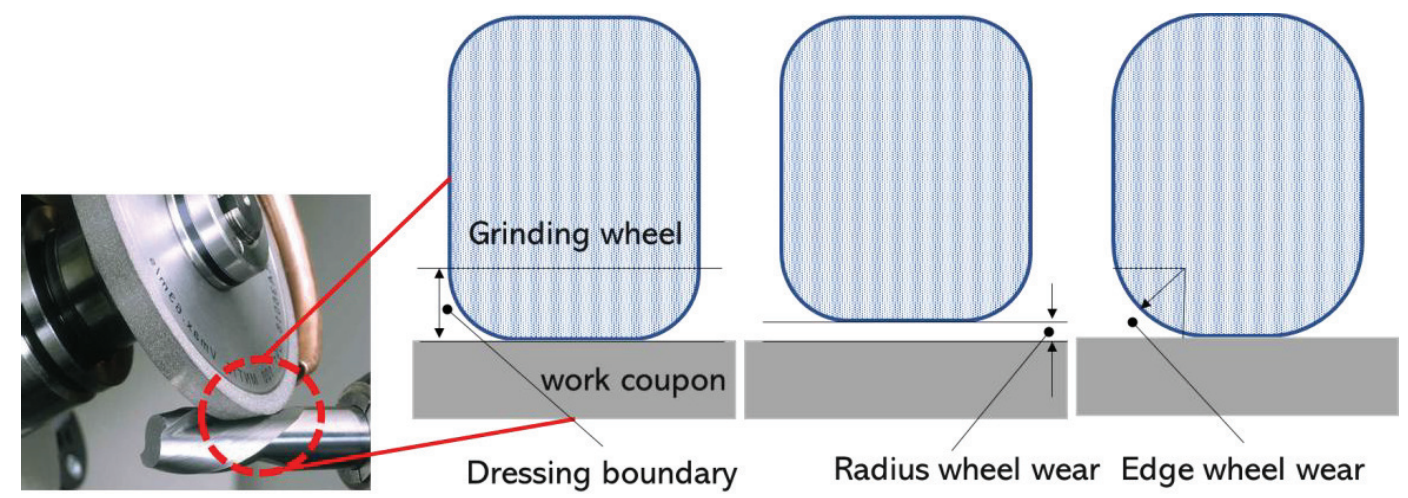

Fig.16 Radius wear and edge wear at a plunge grinding wheel. Reprinted by permission from Elsevier License: Elsevier [70].

Micro geometry effects such as loss of sharpness and, grain break-out lead to a change in surface roughness and higher process energy, which bears the risk of thermal workpiece damage. The thermal damage appears in the form of white layers on the surface and as a tempered zone in sub-surface, affecting sub-surface integrity as shown in Fig.17. Inappropriate grinding of metals will cause undesirable and irreversible change in the microstructure of a surface layer resulting in the workpiece "burn". The sequence of damage initiates with attritious wear as the forces per grain increases which also results in weakening of the grain retention forces causing grit failure and furthermore leading to increased heat generation, which in turn increases wear and damages the workpiece surface integrity. Higher specific material removal rates result in higher single grit loads, which change the wear mechanism from abrasion to grain fracture and total grain break-out. Fig. 18 shows the influence of the material removal rate on wear phenomena in a rigid tool.

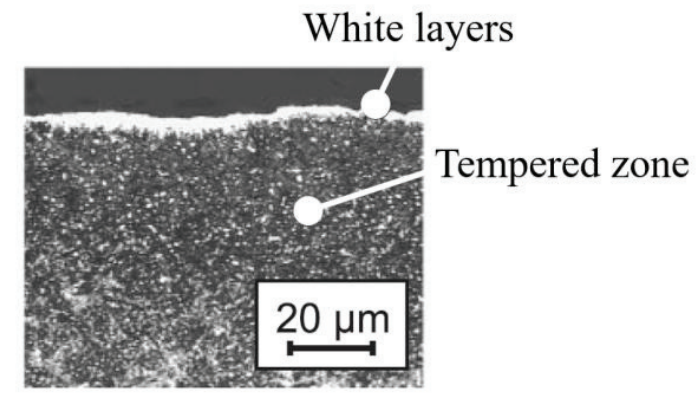

Fig.17 Sub-surface integrity by grinding hardened chrome steel. Reprinted by permission from Elsevier License: Elsevier [71]. 


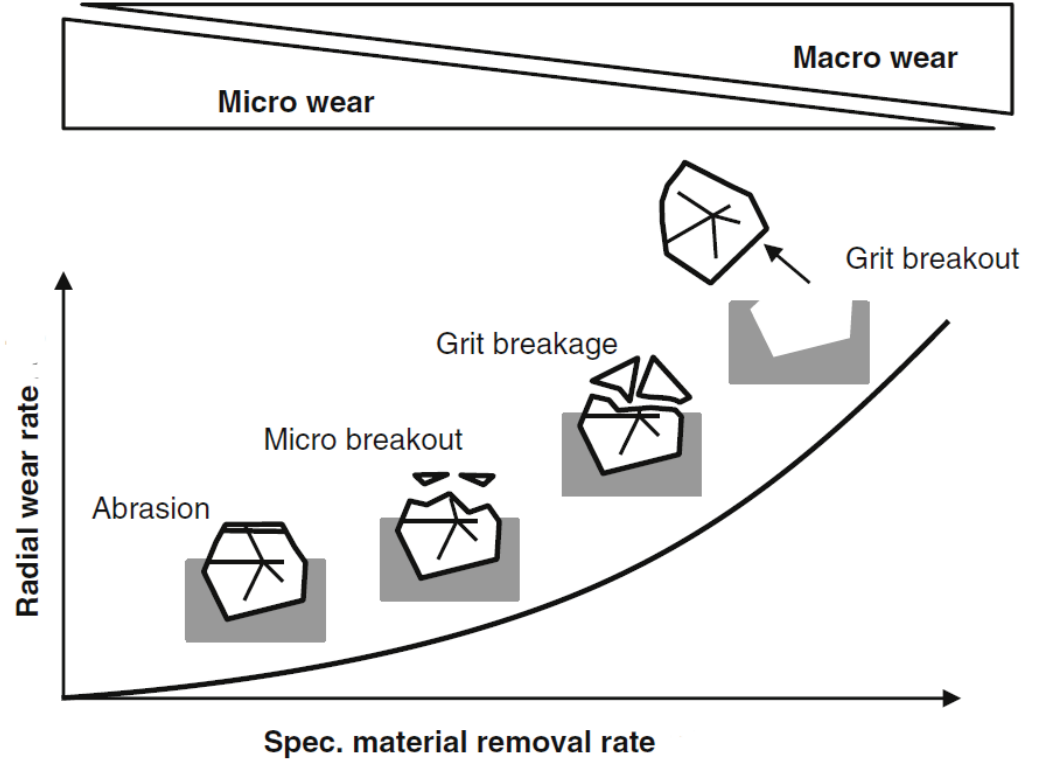

Fig.18 Influence of material removal rate on wear phenomena [72], with kind permission from Springer Science.

Dressing otherwise known as conditioning restores tool sharpness and profile. This process, today, is generally done by a dressing device on the grinding machine in sequence to the grinding process. The dressing process of the grinding tool ensures that the material removal rate, the grinding forces, the surface quality and the material properties of the sub-surface zone are not affected. Dressing techniques will depend on the type of grinding tool [73]. The capability of any dressing technology can be achieved only when the state of the wheel is known with direct measurements such as visual inspection or indirect measurements using sensor signals. Once the tool-life criterion is sensed, the grinding process is interrupted, and the tool is conditioned. Machine clamping influences and interrupt times of the grinding process can be reduced if the dressing methods are modelled to predict the surface topography followed by optimizing the conditioning parameters such as force, wear of the dressing tool, etc.

\subsection{Compliant abrasive tools}

Coated abrasive tools are composed of abrasive grits that are held by a bond on the backing material. Coated abrasive is characterized by three main properties, namely grain particles, adhesives, and backing. The particle grains are bound by adhesive films onto the backing material such as cloths, paper, and fiber. Coated compliant abrasive tools in the form of a disk, flap wheel and belt as shown in Fig. 19 are widely used in industries for secondary finishing operations. An advantage of coated abrasives over other types of abrasive cutting tools is attributed to its compliance as it conforms to the shape of the workpiece surface. Fig.20 shows the abrasive layer structure and common designs of coated abrasive tools.

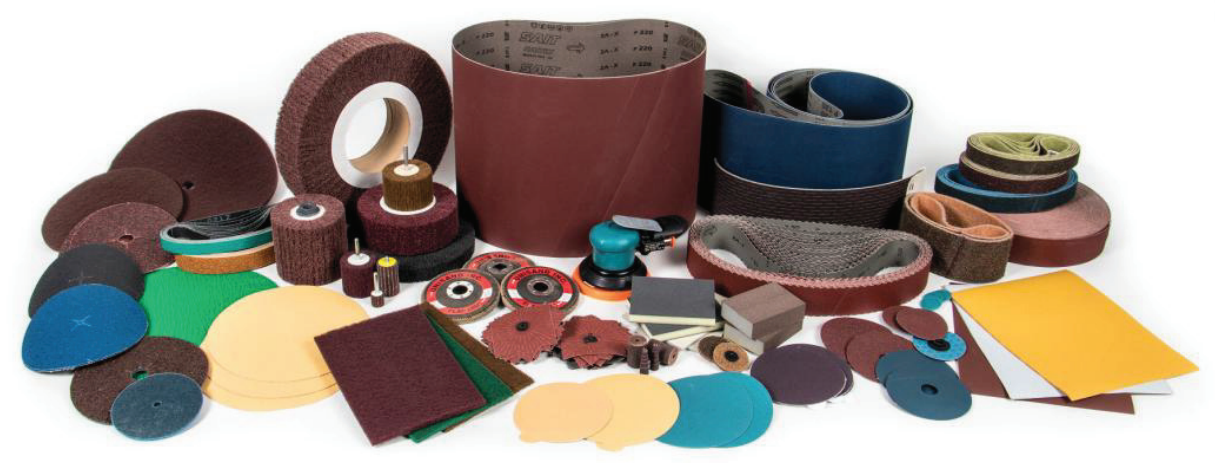

Fig.19 Compliant abrasive tools [70]. 


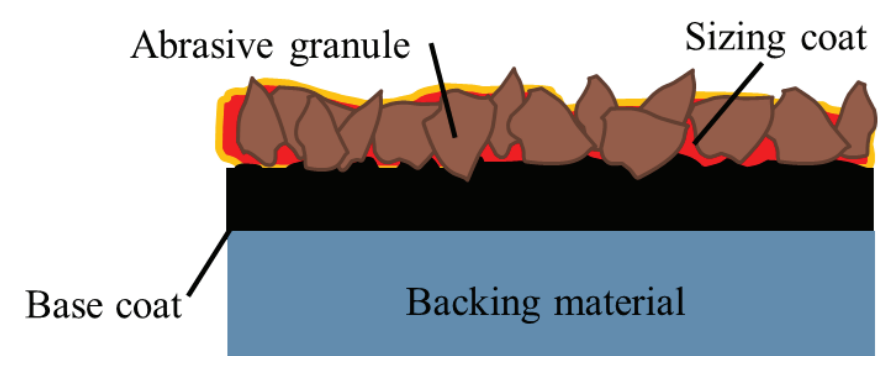

Fig.20 Cross-section of coated abrasive belt.

Main effects plots Signal-to-Noise (SN) ratio
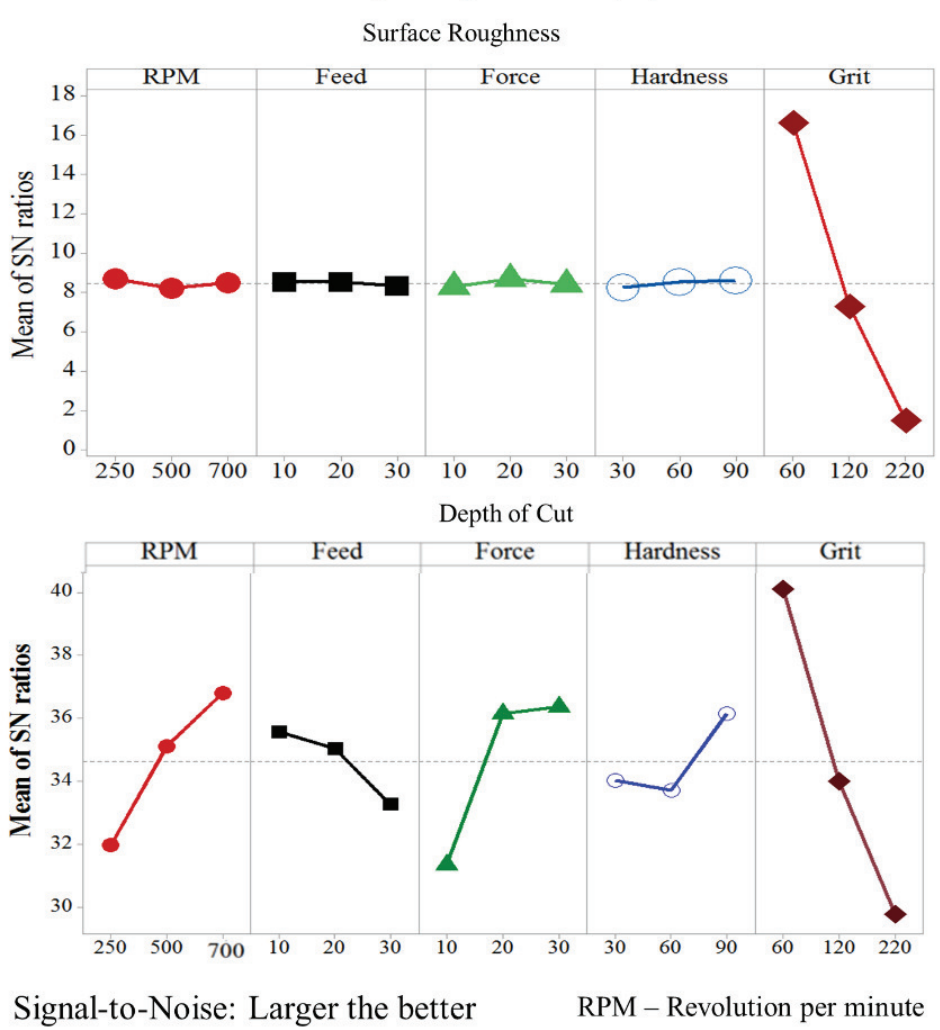

Fig.21 Main effects plot comparison of belt grinding parameters on surface quality and material removal [74].

Like any other abrasive machining, there are many parameters influencing the final ground surface quality, along with the tool topography features. The finishing parameters include speed, infeed rate, workpiece geometry and hardness of backing material, while tool topography features include information such as grit size, grain distance, and wear rate. There have been studies in coated belt grinding tools on the influence of the abrasive film parameters and cutting parameters on the surface quality. The study proved that amid the parameters, the granulometry of abrasive films is highly significant $[66,75]$. Fig.21 shows main effects plot of grit parameter in belt grinding on material removal and surface roughness as compared to other parameters. Apart from the quality of the surface generated, the quantity of the material removed depends on the stiffness of the backing material. In most of the industries, the replacement of coated tools in a finishing process is still based on operator experience. Prior knowledge or real-time information on the state of coated tools that they are underutilized or overused or is due for replacement will help in increasing the performance of the process.

\subsection{Three body abrasive tools}

The applications of state-of-art finishing tools are limited to specific profiles such as concave, convex, flat, and aspherical shapes and are not suitable contenders for finishing internal geometries. Yet, inaccessible areas and complex internal passages can be finished by exciting grains suspended in the form of a slurry. 
Abrasive flow machining (AFM), lapping, media finishing are common processes that polish surfaces based on three body abrasion using a slurry.

The AFM process performs in a manner that is analogous to grinding. As the abrasive slurry conforms to the restrictive passage geometry, it behaves a grinding stone. The velocity of the extruded abrasive slurry is influenced by parameters such as viscosity, pressure, passage size, geometry and length [76]. Based on the viscosity, the difference in metal removal can be of a factor of 300 times [77]. Abrasive concentration, grain size and media viscosity are stated in the literature to have a significant effect on metal removal in the AFM process [78]. Cutting edges of the abrasive grain would wear because of attritious wear leading to wear flats. Concurrently, with attritious wear, individual grains may fracture, generating more smaller cutting edges, thereby reducing the efficiency of the process. The AFM process is not currently suited to mass production as the quality has to checked between cycles; but, it can still be opted towards mass production if in-direct monitoring techniques are proven. There is also a variant of AFM, namely magnetic- field- assisted abrasive flow machining, where the abrading forces are precisely controlled through an external magnetic field.

The metal removal mechanisms in lapping are the result of the reciprocating motion of workpieces over the lapping plate, which removes material in the form of microchips. It is a process reserved for products that demand very tight tolerances of flatness, parallelism, thickness or finish. The compound material, percentage mixture volume, abrasive particle micron size and applied pressure determine the resulting stock removal rate and surface roughness[79]. The lapping plate is generally made of cast iron however nowadays soft material like copper, brass etc. are also used. The abrasive slurry not only functions as transporting medium for abrasive particles and removed microchips but also helps to avoid heating. Different finishes of lapping can be achieved on the basis of a combination of the backing material and abrasive grain used as shown in Fig.22.

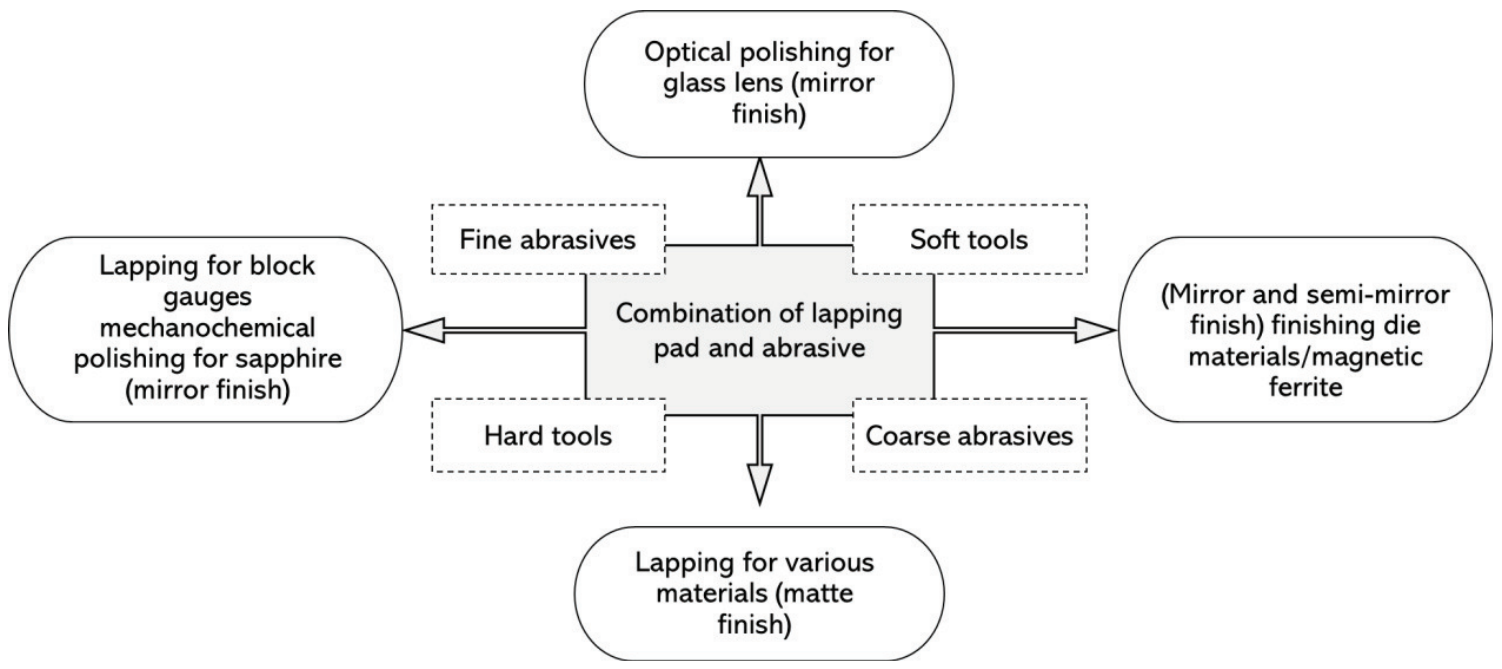

Fig.22 Classification of lapping on the basis of backing and abrasive type. Reprinted by permission from Elsevier License: Elsevier [80].

Media finishing processes involve bulk processing of metallic parts in a recirculating flow of loose, bonded media to modify the surface properties of a workpiece through abrasive contact. The amount of material removed during finishing is generally small and typically micrograms per part in the case of polishing and grams for deburring and edge finishing. Mass finishing processes have been broadly adopted all over industry as the most favourable approach for producing controlled edge and surface finish effects on various types of machined and fabricated components, as shown in Fig.23.

(a)

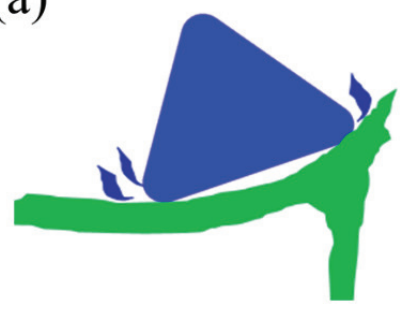

(b)

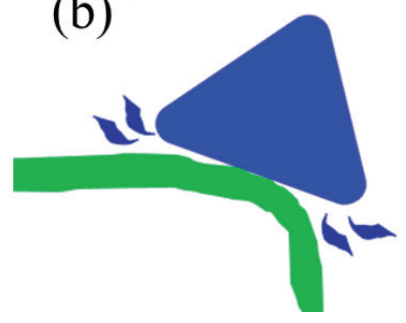

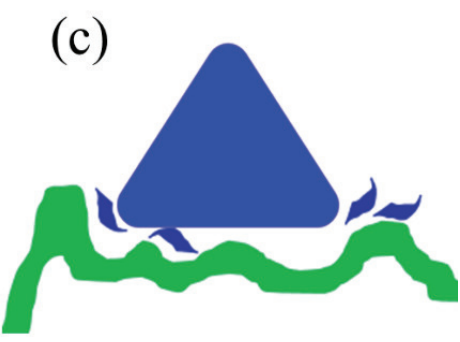


Fig.23 Different abrasive actions like (a) deburring, (b) radiusing and (c) surface smoothing of tri-star media in mass finishing process. Reprinted by permission from Elsevier License: Elsevier [81]

Presently, there are three forms of mass finishing machines in commercial use including tumbling, centrifugal disk and vibratory bowl machines. Of the three, vibratory bowls are the most comprehensively used. Finishing action and effectiveness are influenced by the choice of machine parameters. Process times can vary from several minutes to several hours and while the final surface finish quality is highly dependent on media and compound selection. While some vibratory processes are executed dry; most are performed as wet processes where a water-based solution is a trickle fed into the bowl. Mass finishing is all about pressure and speed. The higher the pressure exerted by the media on the parts, the faster the media "rubs" on the parts, the faster the desired finishing results can be achieved. The finishing processes that involve three body abrasive mechanism are highly randomized. Quantification and modelling of such process are trivial as the interaction in the machining zone is non-consistent.

\section{Sensing Systems}

The best way to investigate the performance of abrasive processes is to measure the physical properties of the generated surface in real-time. As cutting zones are inaccessible, it is unlikely to measure the quality of a workpiece surface in real-time by direct sensing techniques [6]. An indirect measuring technique that is competent in sensing and co-relating evidence related to the machined surface in real-time is always required[82]. The significant advantage of using in-process sensing is that the quality of all machined zone is ensured as compared to the traditionally practiced metrological technique based on random sampling. Integration of a sensor for optimizing manufacturing environment demands reasonable confidence in the sensor as it should be capable of detecting the desired process characteristic consistently. The way by which various sensors are incorporated into the operation of the system is usually a significant factor in the overall design of an intelligent system $[83,84]$. Sensors that are used to retrieve quality information from the process should be in such a way that it does not intrude in the actual process or require extensive alteration on the machine. A multiple-modal sensor system is essential for process scrutinizing to identify the states of the individual components of a machining system. For monitoring in precision manufacturing regime where the tolerances on the surface finish are very tight, this approach is of particular importance [85].

Abrasive finishing process takes place at sub-micrometer to nanoscale dimensions and is capable of achieving surfaces finish of very high quality, i.e. they fall in the precision machining regime. At these levels, the machining process, surface finish, and chip formation are more intimately affected by the material properties such as ductile/brittle behavior. Any kind of mechanical contact of a sensor with any abrasive tool causes severe problems because the grains always tend to grind the material of the touching element. Usage of coolant during the finishing process has a negative impact on the use of optical sensing systems, so they are also not the right choice in industrial production. Therefore, sensor incorporated for real-time data retrieval for any abrasive machining process should be capable of detecting any change in the process with high consistency with minimal distance from the machining zone. Sensor characteristics are determined by the significance of the event to be captured that correlates to the process state [86]. Material to be machined, sensitivity to surface integrity and geometric quality to be achieved, has to be taken into consideration when choosing a suitable sensor[45]. The critical events that are to be monitored and research efforts to capture them for different finishing process are listed in Table 3.

Table 3 Sensor capabilities to predict the events in the machining zone

\begin{tabular}{|c|c|c|c|}
\hline Sensors & Process & Purpose & Reference \\
\hline \multirow{3}{*}{$\begin{array}{l}\text { Piezo- } \\
\text { Acoustic } \\
\text { Emission } \\
\text { (AE) }\end{array}$} & $\begin{array}{l}\text { Abrasive flow } \\
\text { machining }\end{array}$ & $\begin{array}{l}\text { - Study performance characteristics of AFM } \\
\text { - Understand material removal modes }\end{array}$ & [87] \\
\hline & Lapping & $\begin{array}{l}\text { Influence of process parameters on the characteristics } \\
\text { of the AE curve was investigated. } \\
\text { - In-process material removal rate (MRR) monitoring. }\end{array}$ & {$[88,89]$} \\
\hline & $\begin{array}{l}\text { Vibratory media } \\
\text { finishing }\end{array}$ & $\begin{array}{l}\text { - Differentiate normal and scratching types of media } \\
\text { contacts }\end{array}$ & [90] \\
\hline
\end{tabular}




\begin{tabular}{|c|c|c|c|}
\hline & $\begin{array}{l}\text { Abrasive belt } \\
\text { grinding }\end{array}$ & - Tool condition monitoring & {$[75,91]$} \\
\hline & Polishing stone & - Determine the state of the tool & [92] \\
\hline & Abrasive disk & $\begin{array}{l}\text { - Achieve better surface quality } \\
\text { - Contact detection }\end{array}$ & {$[93,94]$} \\
\hline & Grinding & 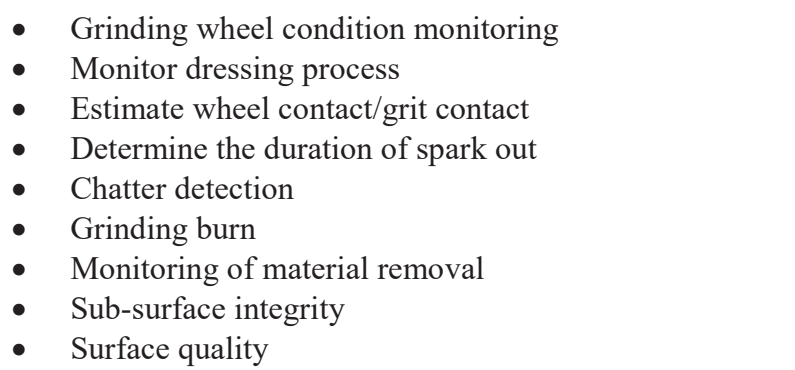 & $\begin{array}{l}{[69,95-} \\
134]\end{array}$ \\
\hline & Honing & - Condition of the honing tools & [135-138] \\
\hline \multirow{5}{*}{ Force } & $\begin{array}{l}\text { Abrasive flow } \\
\text { machining }\end{array}$ & $\begin{array}{l}\text { - Correlate cutting force components on surface } \\
\text { roughness produced }\end{array}$ & [139] \\
\hline & $\begin{array}{l}\text { Abrasive belt } \\
\text { grinding }\end{array}$ & $\begin{array}{l}\text { - Tool condition monitoring } \\
\text { - Endpoint detection of weld seam removal }\end{array}$ & {$[75,140]$} \\
\hline & Grinding & $\begin{array}{l}\text { - Grinding wheel condition monitoring } \\
\text { - } \quad \text { Chatter detection } \\
\text { - } \quad \text { Monitor grinding parameters } \\
\text { - } \quad \text { Grinding burn }\end{array}$ & $\begin{array}{l}{[69,95} \\
96,101 \\
115,119- \\
121,141- \\
143]\end{array}$ \\
\hline & $\begin{array}{l}\text { Vibratory media } \\
\text { finishing }\end{array}$ & $\begin{array}{l}\text { - Study plastic deformation and erosion of a workpiece } \\
\text { surface during media impact }\end{array}$ & [144] \\
\hline & Honing & - Condition of the honing tools & [136] \\
\hline \multirow{4}{*}{ Vibration } & $\begin{array}{l}\text { Abrasive belt } \\
\text { grinding }\end{array}$ & $\begin{array}{l}\text { - Tool condition monitoring } \\
\text { - Endpoint detection of weld seam removal }\end{array}$ & {$[75,140]$} \\
\hline & Flap wheel & - Determine surface finish quality & [145] \\
\hline & Grinding & $\begin{array}{l}\text { - Model relationship between grinding characteristics } \\
\text { - Grd sensor data } \\
\text { - } \text { Monitor dressing process } \\
\text { - Chatter detection } \\
\text { - Surface roughness prediction } \\
\text { - Grinding burn }\end{array}$ & $\begin{array}{l}{[95,96,} \\
100,101 \\
115,119- \\
121,127, \\
129,146, \\
147]\end{array}$ \\
\hline & Honing & - Condition of the honing tools & [136] \\
\hline Temperature & $\begin{array}{l}\text { Abrasive flow } \\
\text { machining }\end{array}$ & $\begin{array}{l}\text { - Correlate temperature and media viscosity on material } \\
\text { removal efficiency }\end{array}$ & {$[148]$} \\
\hline $\begin{array}{l}\text { Microphone } \\
\text { - Airborne }\end{array}$ & $\begin{array}{l}\text { Abrasive belt } \\
\text { grinding }\end{array}$ & - Tool condition monitoring & $\begin{array}{l}{[149,} \\
150]\end{array}$ \\
\hline
\end{tabular}




\begin{tabular}{|c|c|c|c|}
\hline acoustic & Grinding & $\begin{array}{l}\text { - Model relationship between grinding characteristics } \\
\text { and sensor data }\end{array}$ & {$[146]$} \\
\hline \multirow{3}{*}{$\begin{array}{l}\text { Current/ } \\
\text { power }\end{array}$} & Polishing stone & - Determine the state of the tool & [92] \\
\hline & Abrasive disk & - Contact detection & {$[94]$} \\
\hline & Grinding & - Grinding burn & $\begin{array}{l}{[129,} \\
151]\end{array}$ \\
\hline \multirow{3}{*}{$\begin{array}{l}\text { Vision / } \\
\text { optical }\end{array}$} & $\begin{array}{l}\text { Abrasive belt } \\
\text { grinding }\end{array}$ & $\begin{array}{l}\text { - } \quad \text { Endpoint detection of weld seam removal } \\
\text { - } \quad \text { Surface quality/ material removal }\end{array}$ & {$[152-154]$} \\
\hline & $\begin{array}{l}\text { Vibratory media } \\
\text { finishing }\end{array}$ & - Measure surface media velocity fields & {$[155]$} \\
\hline & Grinding & $\begin{array}{l}\text { - } \quad \text { Condition of grinding wheels } \\
\text { - } \quad \text { Changing behaviors of cutting edges }\end{array}$ & {$[156-168]$} \\
\hline
\end{tabular}

Fig.24 also shows the relative frequency of usage of sensors for process monitoring in finishing processes from literature. Acoustic emission sensor has been used more frequently compared to other sensors owing to its sensitivity.

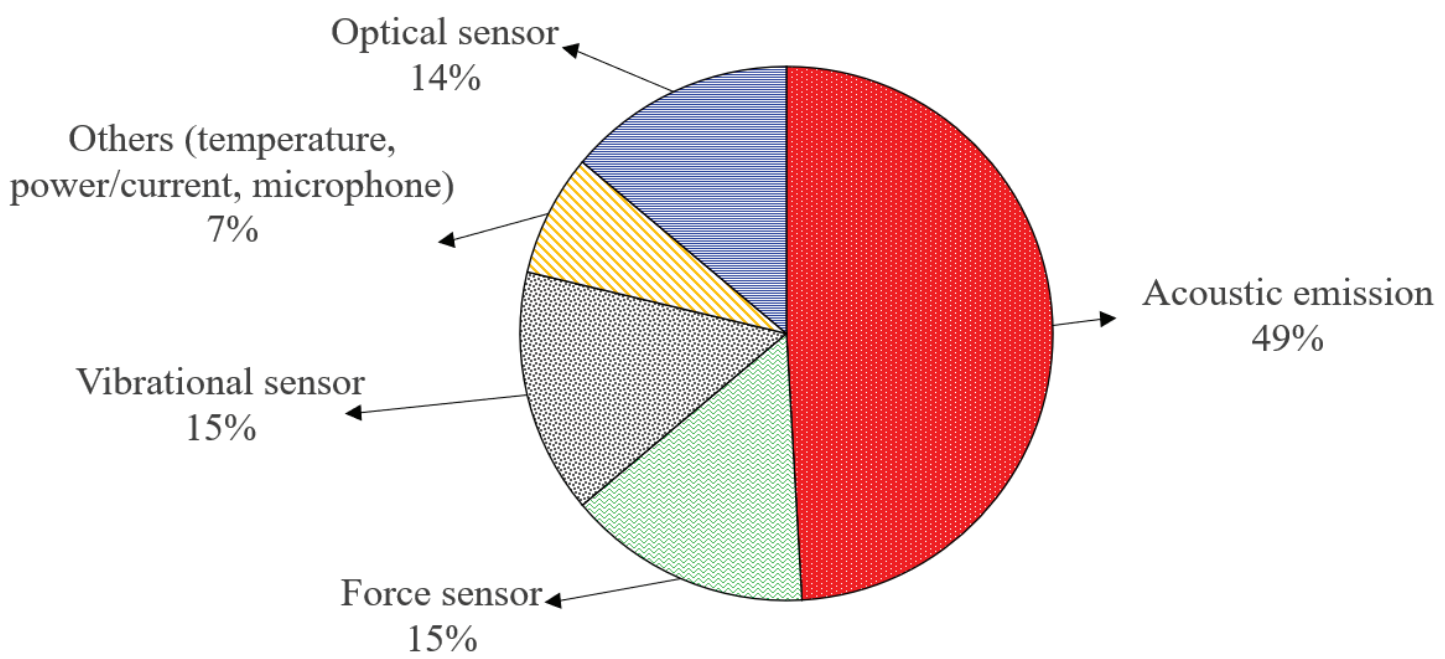

Fig.24 Relative frequency of usage of sensors in monitoring abrasive finishing processes.

Sensitivity loss of force and vibration sensors are higher at a high frequency where most of the micro-cutting components are dominant, as shown in Fig.25. Acoustic emission does not capture low-frequency disturbance signals but is very sensitive to a high-frequency range, which makes it a suitable contender to monitor any abrasive machining process. Nonetheless, the accuracy of the AE sensor depends predominantly upon the detection angle and the distance between the sensor and the workpiece to be measured. 


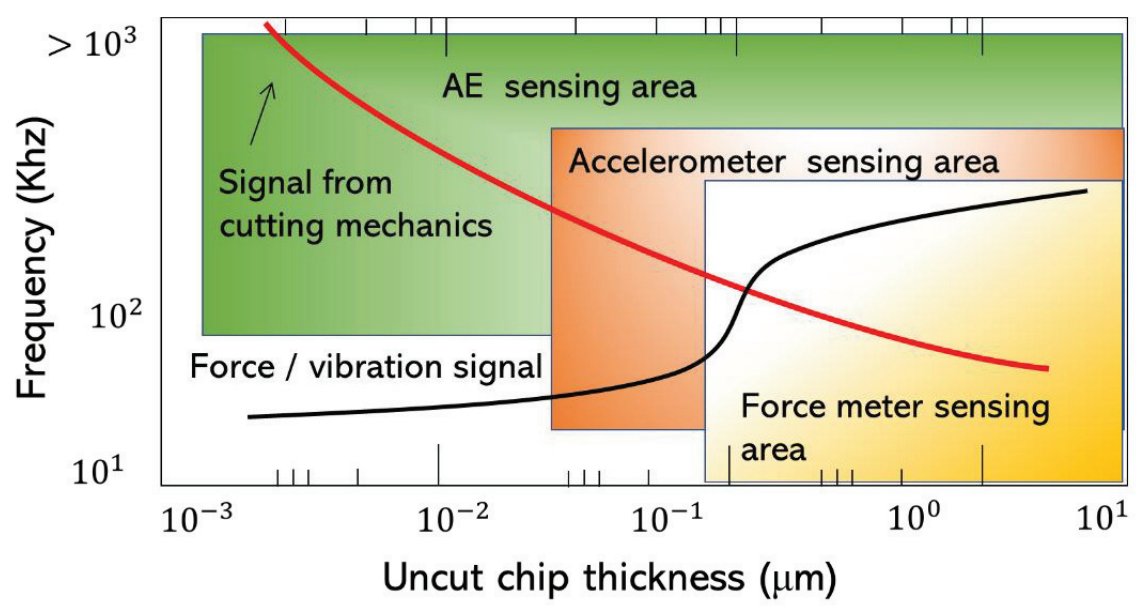

Fig.25 Sensor classification based on operating frequency range and chip thickness [169], with kind permission from Springer Science.

Finishing operations represent a critical and expensive phase of the overall production process. Monitoring such processes rely heavily on sensor characteristics. Research efforts on monitoring the finishing process are more inclined to the retrieval of information about the abrasive tool as it is the factor that degrades with time, which affects the surface quality. Along with the sensors, the application of advanced signalprocessing techniques is required to understand the complex interaction and transition states in the process. Statistical features from the time domain, frequency domain and time-frequency domain analysis are generally combined with AI algorithms in monitoring and modelling of manufacturing processes [6, 170]. The choice of AI technique is decisive to develop reliable models in finishing processes. The choice of AI techniques for a manufacturing process primarily depends on the previous knowledge of the process, nature of the process, information from the sensor and type of experimental samples which is discussed in section 5.

\section{Intelligent Modelling and Monitoring}

The optimal input parameters for realizing the desired output quality like material removal, surface roughness, etc. in machining can be achieved when they are modelled. Theoretical models based on scientific principles are generally the first modelling approach. However, theoretical models are very complicated to develop because of an inadequate understanding and complexity of machining processes [55]. Most prevailing theoretical models for abrasive finishing processes involve assumptions and are restricted to very few measurable quantities and sensors. The stochastic nature of material non-homogeneity, machine/ tool vibration, abrasive tool degradation, chip formation and undefined contacts makes it difficult to model the abrasive processes theoretically. Robust modelling of abrasive processes taking into account all theoretical variables, without assumptions is a trivial task which also consumes time. Theoretical models can be effectively used for abrasive finishing unless the variables/ parameters are not altered drastically, which is not a reality in the industry. Even though a large grey area is present between process conditions and human understanding in finishing processes, they can be modelled in a better way than a theoretical approach using ML and DL techniques. The ML and DL algorithms can recognize patterns and correlations hidden in the data without assumptions.

Apart from modelling the abrasive process using ML and DL techniques, it is also essential to monitor the abrasive process in real-time. Abrasive grains are subjected to tool degradation, as discussed in section 3. Therefore, their states have to be monitored continuously or intermittently. The purpose of process monitoring is so that the operator or the machine itself can react early enough to the undesirable phenomenon's listed in Table 3. The undesirable events that affect the output quality in any process can be identified indirectly from sensors sensitive to those events. The highly complex and non-linear patterns in sensor data from the production line, environmental data and machine tool parameters can be identified using ML and DL techniques. Modelling and monitoring for finishing processes can be established using ML and DL techniques either by regression or classification.

\subsection{Modelling of the finishing process}

Analytical models that explain a highly non-linear relationship with interactions among process variables are challenging to obtain. Performance prediction of any machining process such as surface roughness, 
material removal, depth of cut, etc. could be modelled [171-173] using ML techniques by correlating to machining parameters and sensor data as shown in Fig.26

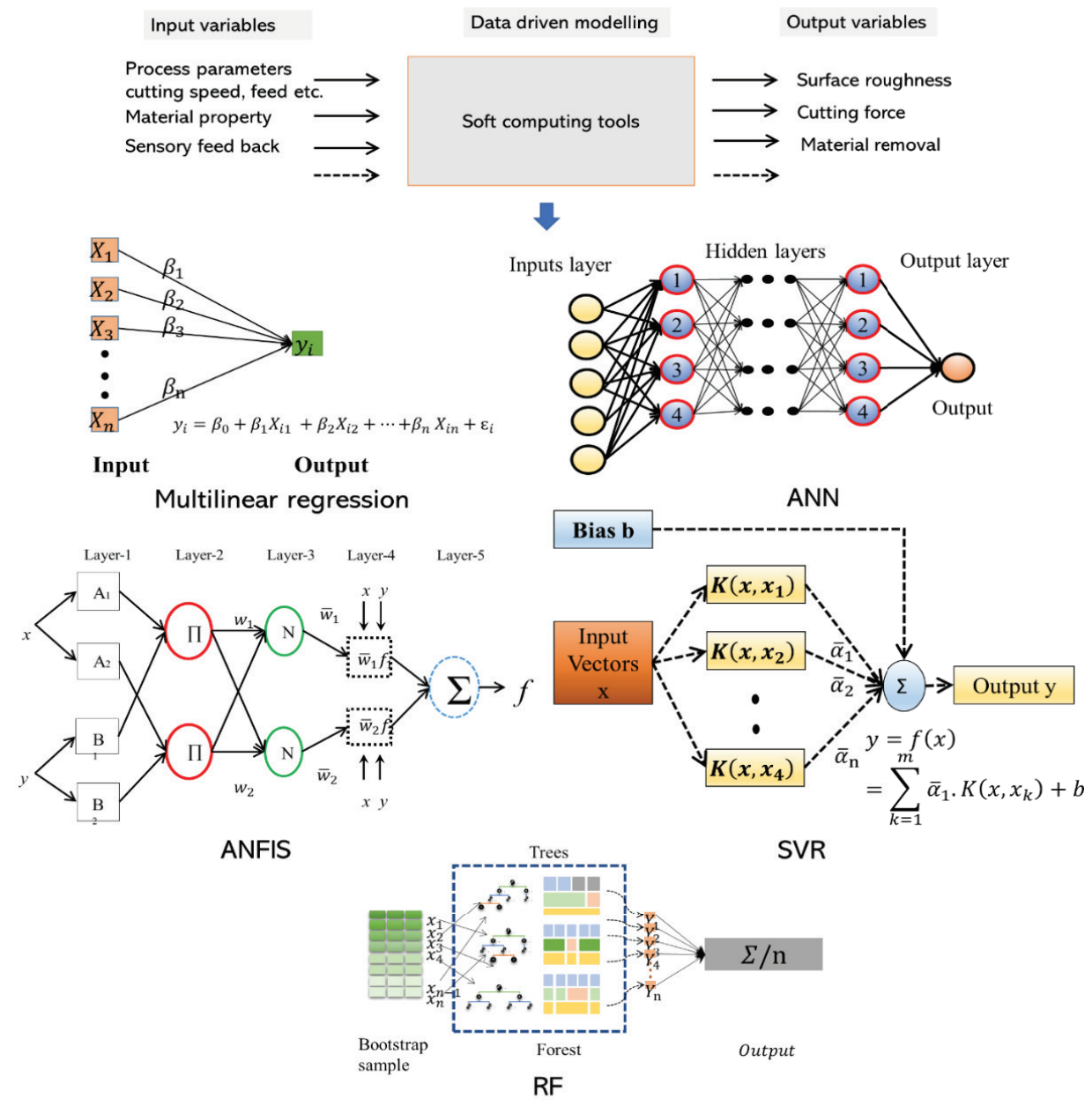

Fig.26 Schematics of applications of ML in modelling machining processes [171], with kind permission from Springer Science.

Some advantages of such an approach include minimum need of understanding of the underlying mechanisms. But it has to be noted that in developing statistical models for process control, it is vital that the model is supplied with input parameters that have maximum impact for achieving the desired objective. As far as statistical modelling of the machining process, it requires predictor variables such as process parameters, sensor data, etc. and response variable such as material removal, surface roughness, etc. Artificial intelligence techniques, such as ANN and expert systems, have been increasingly used to statistical model process behavior in areas where analytical models are unavailable.

Table 4 Data-driven modelling of finishing processes.

\begin{tabular}{|l|l|l|l|l|}
\hline Process & $\begin{array}{l}\text { Modelling } \\
\text { objective }\end{array}$ & Parameter & Algorithm & Reference \\
\hline \multirow{5}{*}{ Grinding } & Predicting burns & $\begin{array}{l}\text { Dressing, wheel grade, grit size, } \\
\text { cut depth, table speed, coolant }\end{array}$ & Fuzzy & {$[174]$} \\
\cline { 2 - 5 } & Time to burn & $\begin{array}{l}\text { Speed, power, Infeed and } \\
\text { diameter }\end{array}$ & ANN & {$[175]$} \\
\cline { 2 - 5 } & $\begin{array}{l}\text { Temperature to } \\
\text { burn }\end{array}$ & $\begin{array}{l}\text { Grinding force, sensor Root } \\
\text { Mean Squared (RMS), time }\end{array}$ & ANN & {$[115]$} \\
\cline { 2 - 5 } & $\begin{array}{l}\text { Vibrations } \\
\text { prediction }\end{array}$ & Speed, feed rate and depth of cut & ANFIS & {$[147]$} \\
\cline { 2 - 5 } & Surface roughness & Speed, feed rate and depth of cut & ANFIS & {$[147]$} \\
\cline { 2 - 5 } & Power spectral density & ANFIS & {$[176]$} \\
\hline
\end{tabular}




\begin{tabular}{|l|l|l|l|l|}
\hline & & Process parameters & Fuzzy & {$[177-179]$} \\
\cline { 2 - 5 } & $\begin{array}{l}\text { Model parameter } \\
\text { to sensor data }\end{array}$ & $\begin{array}{l}\text { Power drawn, feed rate, surface } \\
\text { roughness }\end{array}$ & $\begin{array}{l}\text { Multiple } \\
\text { regression, } \\
\text { ANFIS }\end{array}$ & {$[146,180]$} \\
\hline $\begin{array}{l}\text { Abrasive } \\
\text { waterjet } \\
\text { machining }\end{array}$ & Surface roughness & $\begin{array}{l}\text { Traverse speed, waterjet } \\
\text { pressure, distance, grit size and } \\
\text { flow rate }\end{array}$ & ANN & {$[181]$} \\
\hline $\begin{array}{l}\text { Abrasive } \\
\text { flow } \\
\text { machining }\end{array}$ & Airflow output & $\begin{array}{l}\text { Weight, surface finish, airflow, } \\
\text { machine setting, Media } \\
\text { condition, Temperature }\end{array}$ & ANN & {$[182]$} \\
\cline { 2 - 6 } & $\begin{array}{l}\text { Surface finish, } \\
\text { performance }\end{array}$ & $\begin{array}{l}\text { Workpiece condition, machining } \\
\text { parameters, media characteristics }\end{array}$ & ANN & {$[183]$} \\
\hline Belt grinding & Material removal & $\begin{array}{l}\text { Wheel speed, hardness, feed, } \\
\text { force, grit size }\end{array}$ & $\begin{array}{l}\text { ANFIS, RF, } \\
\text { Stepwise- } \\
\text { regression }\end{array}$ & {$[66,74]$} \\
\hline $\begin{array}{l}\text { Vibratory } \\
\text { media } \\
\text { finishing }\end{array}$ & Material removal & $\begin{array}{l}\text { Workpiece density, time, media } \\
\text { type, acceleration }\end{array}$ & ANN & {$[184]$} \\
\hline
\end{tabular}

Previous works on modelling different finishing processes are listed in Table 4. Most of the statistical modelling work for finishing processes have been accomplished with ANN and Adaptive Neuro-Fuzzy Inference System (ANFIS) that can map a highly non-linear relationship, which is the characteristics of any abrasive process.

Nandi and Banerjee [179] proposed a neuro-fuzzy model to predict power requirement and surface roughness better than mathematical models in cylindrical plunge grinding process using input variables such as wheel speed, feed rate and work speed. Fig. 27 shows the proposed neuro-fuzzy architecture with eight $(2 \times 2 \times 2)$ rules with each input variables has two linguistic values medium and low. A three-layer fuzzy model was designed by Ali and Zhang [177] to correlate surface roughness using the fuzzy rules generated based on experimental observations and recommendations from wheel manufacturers.

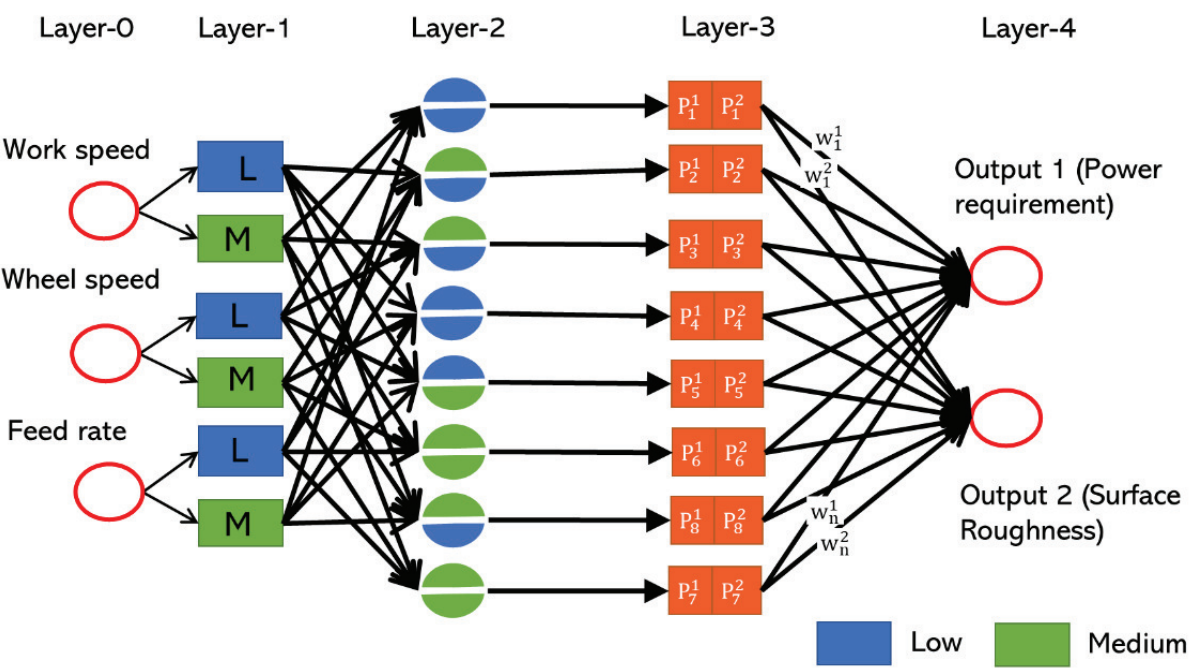

Fig. 27 Architecture of neuro-fuzzy having 3 inputs-2 outputs with eight rules to model plunge grinding. Reprinted by permission from Elsevier License: Elsevier [179].

A back-propagation-type neural network with mean square error (MSE) loss function as shown in Fig.28 was used to model the time-to-burn with input variables such as work speed, in-feed, grinding power and the working diameter as input to neurons in the first layer [175]. Similarly, correlation of process variables with temperature to burn in grinding high speed steel has also been established [115]. Though ANN correlates the input and output variables with good confidence for abrasive processes based on literature, it has been stated in such a way that it essentially functions as a 'black box'. There have been minimum efforts so far on retrieval of information of the patterns learnt by each node of the network. Lezanski [95] had optimized the network by applying weight pruning method to eliminate nodes to classify the condition of the grinding wheel. $z$, there are 
no reports on a specific rule for determining the structure of the ANN and most of the work on abrasive processes are configured based on trial and error.

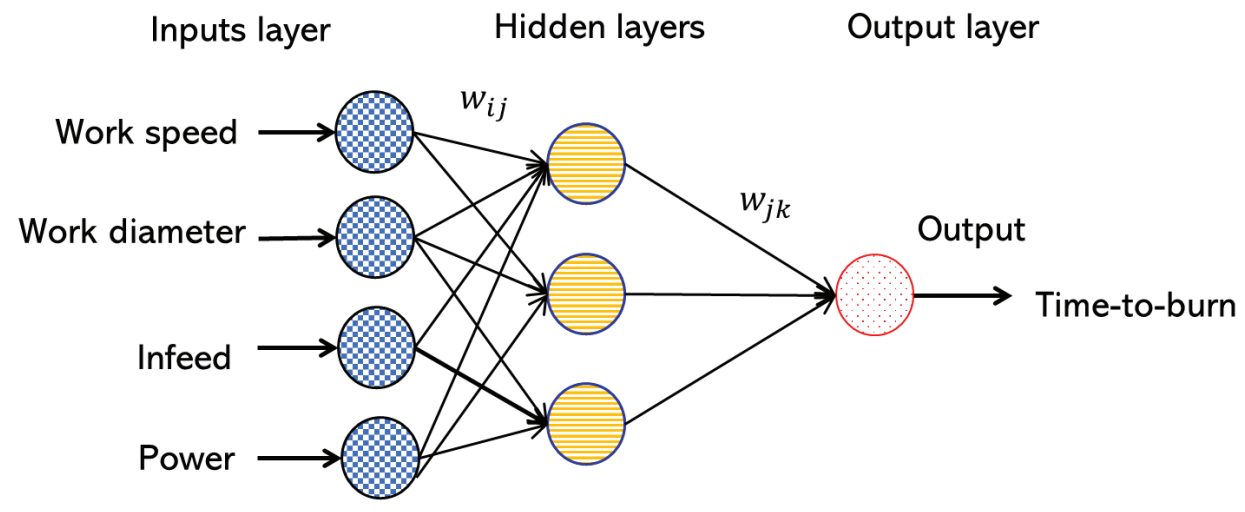

Fig.28 A typical neural-network structure with the input and output variables. Reprinted by permission from Elsevier License: Elsevier [175].

Surface roughness and material removal have also been modelled for processes such as belt grinding, abrasive jet machining, grinding, etc. [66, 74, 147, 181]. Vijayaraghavan and Castagne [184] modelled material removal rate (MRR) in mass finishing process using the ANN with inputs as workpiece density, machine acceleration, media factor, and processing time. Apart from surface roughness model and, MRR, the relationships between grinding parameters and signal characteristics of sensor like AE and accelerometer have been optimized by multiple regression [146]. The authors have also explored other regression modelling techniques such as ANFIS, RF apart from ANN to estimate material removal based on parameters in the belt grinding process [74]. Based on the evolution of membership function after training in ANFIS and Out-of-bag (OOB) error score in RF, it was evident that the grit size factor played a dominant role. Extraction of such information from ANN is trivial.

For establishing a generalized data-driven model, is it critical to establish the parameter level using Design of Experiments (DoE's). The level of the individual parameters determines the mapping function of these data-driven models. Reduction of the parameter space with DoE is seen as a simple approach to statistical model the abrasive finishing process [185-188]. Apart from establishing equal importance for the parameter levels, emphasize should also be put on the volume of the data set. Besides, modelling of the finishing process using ML algorithms, they have also been used to optimize the parameter to maximize material removal, reduce production time and cost [189-192]. With manufacturing industries evolving and new materials been introduced rapidly, modelling process analytically, especially for abrasive finishing, will be a challenging task. Therefore, data-driven modelling based on ML algorithms will be a promising alternative. As far as modelling of abrasive processes in metals, sparse efforts have been put on modelling using ML techniques such as RF, Support Vector Regression (SVR), etc [17]. DL algorithms have never been tried or reported in the literature, which is also a gap that requires bridging by the research community.

\subsection{Monitoring of finishing process}

In the real-time monitoring of modern automated machining systems, ML and DL methods play a primary role. A decision-making process in monitoring is based on the relationship between the process/tool conditions and the feature-bearing sensor signals. In-direct sensors, as discussed in Section 4, have demonstrated a high degree of confidence in characterizing various phenomena, hence, lending credence to its suitability for abrasive process monitoring. Fig.29 shows all the building blocks which are required for process monitoring [170] and negligence of significant factors in each block will affect the performance of the developed system. 


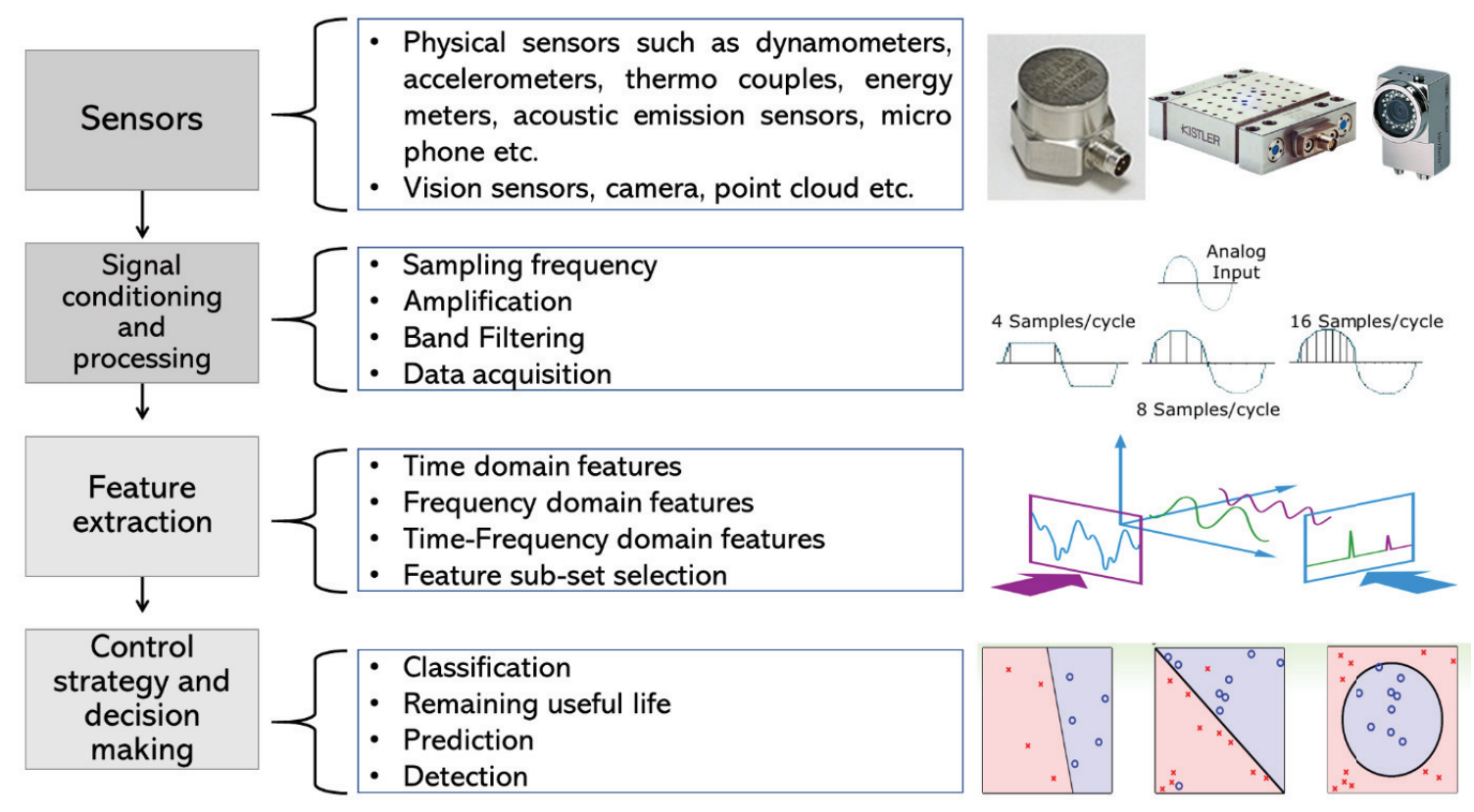

Fig.29 Components of a monitoring system.

Selection of proper sensors and its operating range is determined by the significance of the event to be captured that correlates to the process state [86]. As a rule of thumb, data acquisition rate is based on the Nyquist-Shannon theorem which states that sampling rate should be at two times that of the maximum frequency range that we are interested in [86]. Failure to fulfil this requirement will result in aliasing of the reconstructed signal. Filtering should be carried out to eliminate unwanted attributes and undesired components that may be present within the signal. Filtering can be an offline or an online process depending on the hardware capability. Sensor data in the raw form may be challenging to quantify, and conversion to other physical quantities is required for more straightforward analysis. Time-domain and frequency-domain feature representation are obtained through mathematical functions from which the conversion from continuous to discrete data is realized. Conversion of the signal from the time-domain into the frequency-domain will facilitate us to focus on frequently occurring dominant frequency bands, which will give further insight into the process. Feature extraction methods can be roughly divided into the time domain, frequency domain and time-frequency domain. Distribution of features used for analysis, characterization and monitoring of abrasive finishing process is shown in Fig. 30. The features extracted from in-direct measurements such as cutting, forces, vibrations or AE measurements can be more effective monitoring phenomena such as tool wear and surface quality when combined with AI techniques. The AI techniques process the signal features and accomplish a pattern association assignment, thereby establishing a correlation between the signal feature and appropriate monitoring process state.

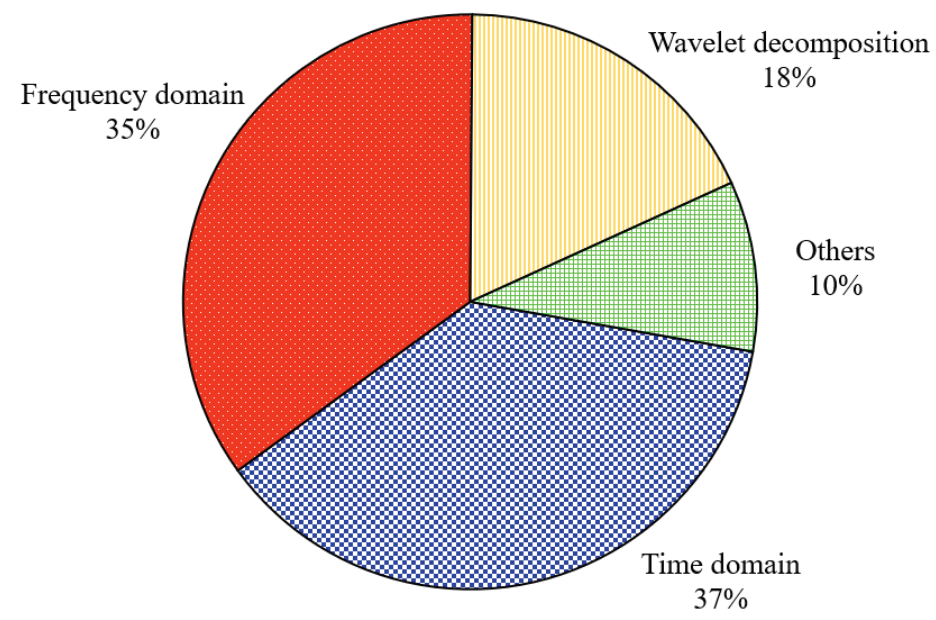

Fig. 30 Distribution of features used for analysis and characterization of the abrasive finishing process. 
Tool wear and surface quality, which are interrelated have been significant indicators of finishing process performance, therefore it is critical to monitor those. Previous works on monitoring different finishing processes are listed in Table 5. Generally, monitoring of machining process ranges from simple threshold limit value being exceeded [193] to statistical comparisons to systems. Owing to the complexity involved in the abrasive processes a sophisticated decision-making algorithm, rather than a simple threshold technique, may thus be necessary.

Table 5 Data-driven monitoring of finishing processes.

\begin{tabular}{|c|c|c|c|c|}
\hline Process & $\begin{array}{l}\text { Monitoring } \\
\text { objective }\end{array}$ & Sensor feature & Algorithm & Reference \\
\hline \multirow{22}{*}{ Grinding } & \multirow{7}{*}{ Workpiece burn } & $\begin{array}{l}\text { Band power, Kurtosis Skewness and } \\
\text { autoregressive (AR) coefficients }\end{array}$ & ANN & [194] \\
\hline & & Wavelet packet transform & Fuzzy & [117] \\
\hline & & $\begin{array}{l}\text { RMS, Mean value dispersion, } \\
\text { Autocorrelation, Kurtosis and } \\
\text { skewness }\end{array}$ & Fuzzy & {$[133,195]$} \\
\hline & & $\begin{array}{l}\text { Static power, RMS, FFT and } \\
\text { dynamic power }\end{array}$ & ANN & {$[196,197]$} \\
\hline & & $\begin{array}{l}\text { Wavelet packet decomposition } \\
\text { features }\end{array}$ & Sparse autoencoder & {$[121]$} \\
\hline & & FFT and Wavelet Transform & SVM & {$[151]$} \\
\hline & & STFT & $\begin{array}{l}\text { Genetic } \\
\text { Programming }\end{array}$ & {$[130]$} \\
\hline & \multirow{10}{*}{ Wheel condition } & $\begin{array}{l}\text { RMS, amplitude, ring-down count, } \\
\text { average signal level }\end{array}$ & $\begin{array}{l}\text { DT, ANN, } \\
\text { and support vector } \\
\text { machine }\end{array}$ & {$[198,199]$} \\
\hline & & Wavelet-based energy features & $\begin{array}{l}\text { Genetic Algorithm } \\
\text { (GA) }\end{array}$ & {$[102]$} \\
\hline & & $\begin{array}{l}\text { Ratio of power features in } \\
\text { frequency bands }\end{array}$ & Fuzzy & {$[110]$} \\
\hline & & Statistical and spectral & Neuro-fuzzy & {$[95,96]$} \\
\hline & & STFT analysis & SVM & {$[200]$} \\
\hline & & $\begin{array}{l}\text { Autoregressive and discrete wavelet } \\
\text { decomposition }\end{array}$ & $\begin{array}{l}\text { K-Nearest Neighbor } \\
(\mathrm{kNN})\end{array}$ & {$[118]$} \\
\hline & & $\begin{array}{l}\text { Autocorrelation and partial } \\
\text { autocorrelation }\end{array}$ & $\begin{array}{l}\text { Minimum distance } \\
\text { classifier }\end{array}$ & {$[201]$} \\
\hline & & Discrete wavelet decomposition & HMM & {$[202]$} \\
\hline & & Wavelet analysis & SVM & {$[113,203]$} \\
\hline & & $\begin{array}{l}\text { Time-domain and frequency- } \\
\text { domain features }\end{array}$ & $\begin{array}{l}\text { Long } \\
\text { Short-Term Memory }\end{array}$ & {$[120]$} \\
\hline & \multirow{4}{*}{ Chatter vibration } & $\begin{array}{l}\text { Static power, RMS, FFT and } \\
\text { dynamic power }\end{array}$ & ANN & {$[196,197]$} \\
\hline & & FFT spectrum & ANN & [204] \\
\hline & & $\begin{array}{l}\text { Time-domain and frequency- } \\
\text { domain features }\end{array}$ & SVM & [129] \\
\hline & & STFT & Genetic Programming & {$[130]$} \\
\hline & Surface roughness & $\begin{array}{l}\text { Wavelet transform feature from two } \\
\text { bands }\end{array}$ & SVM & {$[205]$} \\
\hline Deburring & Surface quality & $\begin{array}{l}\text { Wavelet decomposition and } \\
\text { Welch's spectrum }\end{array}$ & ANFIS & {$[145]$} \\
\hline \multirow{5}{*}{$\begin{array}{l}\text { Belt } \\
\text { grinding }\end{array}$} & \multirow{3}{*}{ Tool wear } & $\begin{array}{l}\text { Time-domain and frequency- } \\
\text { domain features }\end{array}$ & $\begin{array}{l}\text { SVM, kNN, ANN, } \\
\text { DT, Naive Bayes }\end{array}$ & {$[75]$} \\
\hline & & Time-frequency spectrum image & $\mathrm{CNN}$ & [149] \\
\hline & & Discrete Wavelet Decomposition & ANN & {$[150]$} \\
\hline & $\begin{array}{l}\text { Condition } \\
\text { monitoring of belt } \\
\text { tool }\end{array}$ & Time-domain & $\mathrm{RF}$ & [91] \\
\hline & Detection of weld & Wavelet features & SVM, kNN, ANN, & {$[74]$} \\
\hline
\end{tabular}




\begin{tabular}{|l|l|l|l|l|}
\hline \multirow{2}{*}{} & state & & DT, Naive Bayes & \\
\cline { 3 - 5 } & Image pixels & $\begin{array}{l}\text { Encoder-Decoder } \\
\text { CNN }\end{array}$ & {$[152]$} \\
\hline $\begin{array}{l}\text { Polishing } \\
\text { stone }\end{array}$ & $\begin{array}{l}\text { Tool change and } \\
\text { surface roughness }\end{array}$ & Statistical and PCA features & ANN & {$[92]$} \\
\hline
\end{tabular}

As listed in Table 5, the statistical features based on frequency and time-frequency are mostly used as input to trains models to monitor the finishing process. Wavelet decomposition and Welch's spectrum estimate were used as features for training ANFIS with least square estimation to the predict surface finish quality in deburring [145]. Alexandre et al. [110] predicted the conditions of the grinding wheel topography in real-time using frequency domain analysis and fuzzy system. Classification of undesirable events such as burning, chatter vibration from the normal condition in the grinding process has also been achieved using ANN based on AE sensor data [197]. The architecture of the ANN built in this study had RMS peak, Fast Fourier Transform (FFT) peak, the count out of the threshold, and the standard deviation of AE signals as the input neurons and burning, chatter vibration and normal condition as the output neurons as shown in Fig.31. The feed-forward back propagation neural network and fuzzy logic have been combinedly used to classify the condition of the grinding wheel where the former has been used for feature subset selection, and the latter is used for classification [95].

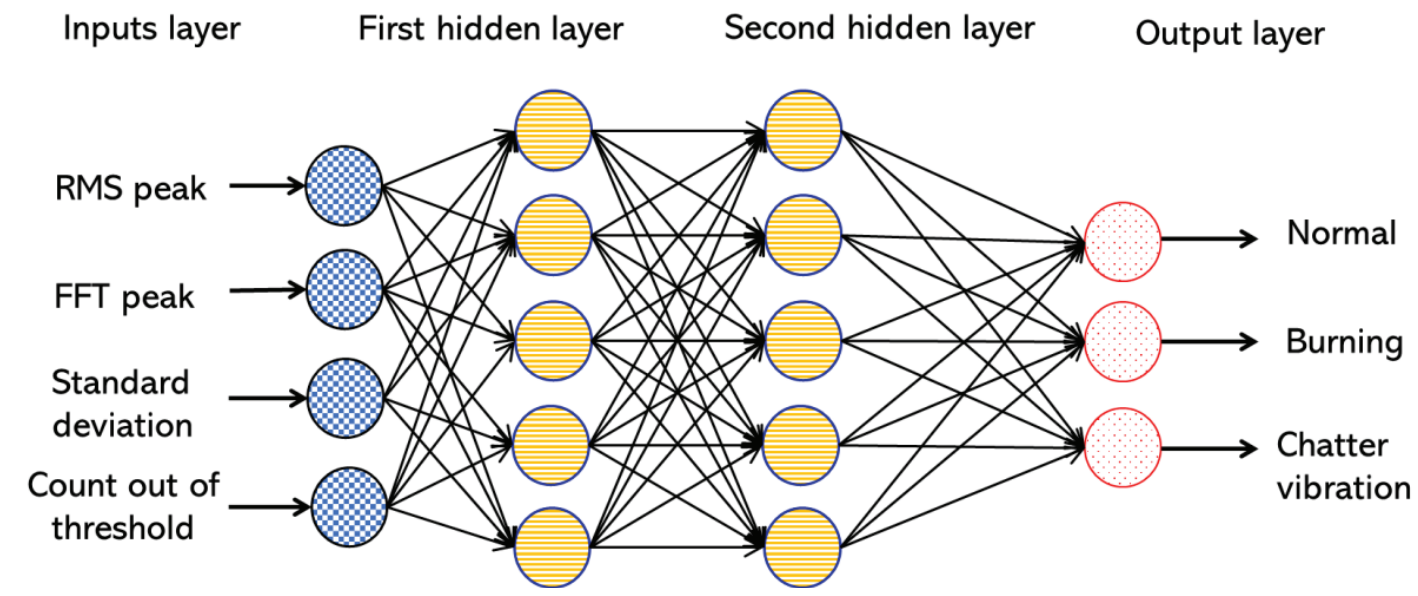

Fig.31 The architecture of the neural network used in this study. Reprinted by permission from Elsevier License: Elsevier [197].

Apart from ANN, neuro-fuzzy and fuzzy systems other algorithms such as SVM, Naive Bayes, DT, HMM have been reported in the literature for monitoring finishing processes. SVM algorithm using Radial Basis Function (RBF) kernel has been used to classify sharp and worn wheels using wavelet features acquired from AE [113]. Monitoring the condition of grinding wheel have also been accomplished by building the distance matrix using HMM and then applying partition-based clustering methods [202]. Feature selection and optimization form an integral part during training models for monitoring. Reducing feature space facilitates computation cost and helps to identify process state nearly real-time. Few works on feature selection and reduction using Genetic Algorithms (GA), Ant Colony Optimization (ACO), etc. for abrasive process monitoring have been formulated $[75,95,118,206]$. The major concentration of modelling and monitoring of finishing process in metals have been performed using ANN followed by neuro-fuzzy and fuzzy, as shown in Fig.32. 


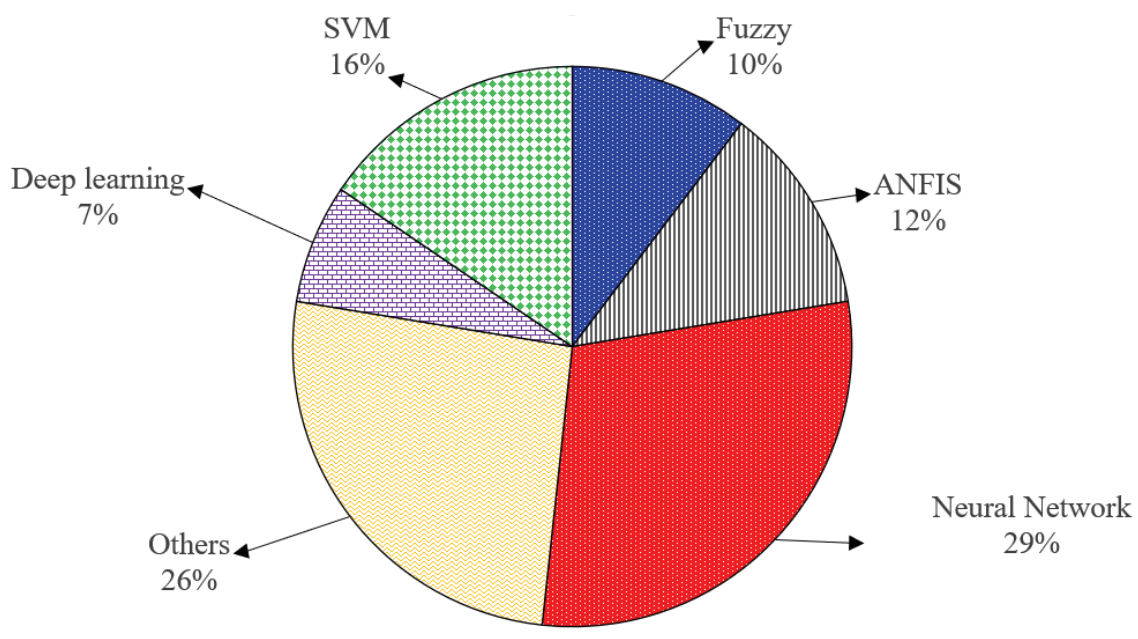

Fig.32 Relative frequency of usage of soft-computing methodologies in monitoring and modelling abrasive finishing processes.

Unlike modelling abrasive processes using only ML's, for monitoring, DL based decision-making algorithms have been established and reported in the literature [120, 149, 152]. Encoder-decoder framework as shown in Fig. 33 has been developed by modifying conventional VGG-16 network to predict and localise the state of weld profile from images captured during belt grinding process [152]. The trained network was able to classify the state of weld profile geometry evolution irrespective of the variable grinding parameters.

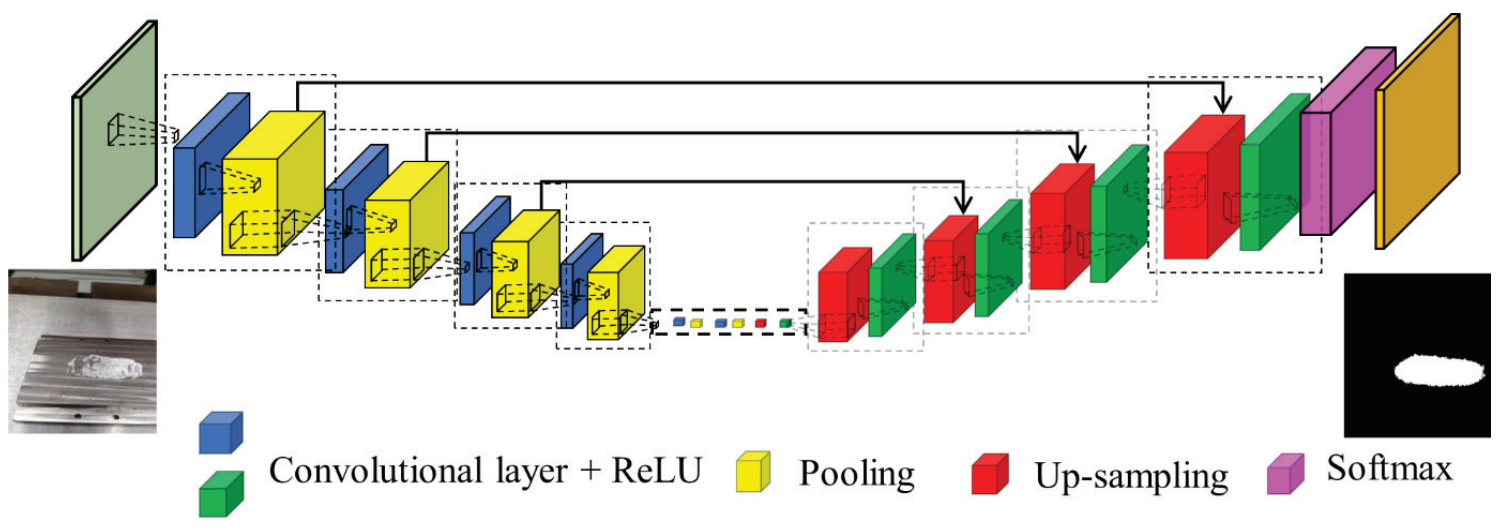

Fig. 33 Machine-vision based encoder-decoder convolutional neural networks architecture to monitor weld profile geometry. Reprinted by permission from Elsevier License: Elsevier [152].

The Deep Convolutional Neural Network (DCNN) has also been used to predict tool wear in belt grinding by converting microphone sensor signals into using time-frequency spectrum image representation as network input [149]. A comparative study in terms of prediction accuracy in wheel wear monitoring between conventional ML and DL has also been explored [120]. Most works on using AI for monitoring and modelling are exercised more on the grinding process compared to other abrasive finishing processes which require immediate attention among the research community, as shown in Fig. 34. 


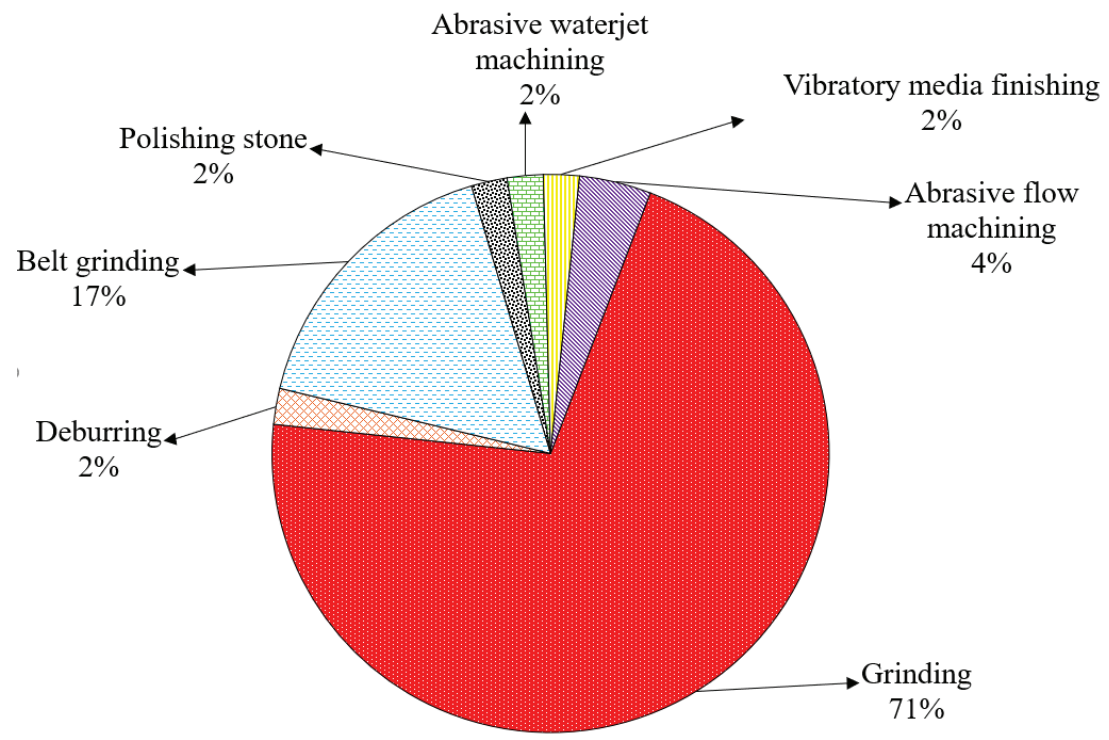

Fig. 34 Usage of soft-computing methodologies in monitoring and modelling different abrasive finishing processes from literature.

\section{Conclusions}

A potential way of taking maximum advantage of the abrasive finishing is to model and monitor the characteristic features of the process. With manufacturing techniques such as AM of metals getting industrialized [207] and newer material alloys developed, the building of comprehensive analytical models with simplified assumptions is not feasible in abrasive finishing. In that perspective, data-driven approaches always have an edge compared to analytical models. Data-driven approaches add value to the whole manufacturing chain as they are also a core component of Industrie 4.0 concept. The probable further research tendency and trends on data-driven monitoring and modelling for abrasive finishing are discussed below.

- Though efforts have been made to understand the parameters involved in different finishing processes, effort on statistically model these processes using AI techniques have been minimum. Most AI techniques popular among the research communities have not been entirely exploited for modelling of abrasive finishing processes. It is also to be noted that the complexity of the abrasive processes and the varieties in its dynamics from one application to another limit us to develop a universal model, making AI model-based control applicable only to a specific application.

- Most of the research work for monitoring faults and defects in abrasive finishing processes have been performed based on categorical classification. A minimum effort has been put to model or predict phenomenon's and mechanisms that degrade with time, especially on predicting remaining useful life of the abrasive tool. Knowing the remaining useful life of coated tools would greatly facilitate tool replacement decision-making process.

- Until today, AI models developed for finishing processes are governed by parameters levels, sensor data, experimental conditions and any drastic change of conditions will result in a loss in performance of the model. Therefore, emphasis should be taken more on developing evolutionary algorithms that can adapt changes and predict unknown space for modelling and monitoring.

- With the ongoing newly developed abrasive processes, besides the improvement of existing ones, it is obviously imperative to understand the underlying physics among the process for valid sensor selection, feature extraction and choice of soft computing techniques. Efforts to augment physical understanding of the processes using data-driven models are still in the early stages, which requires special attention from the research communities.

- Most works in modelling and monitoring had been explored using conventional machine learning algorithms in the literature. Alternatively, deep learning algorithms could also be explored to model and monitor the finishing process. Most literature works that employ AI for finishing processes are proven at laboratory scale. Migrating the AI models to production plants might cause them to fail as it would be unfamiliar with new scenarios. This emphasizes on using transfer learning algorithms to retrain them with the new scenarios augmenting them with the previous knowledge.

- Finally, modelling and self-monitoring implementation of manufacturing processes has to support the development of interoperable ecosystem relevant to the Industry 4.0 concept with ease. 


\section{References}

[1] T. Wuest, C. Irgens, and K.-D. Thoben, "An approach to monitoring quality in manufacturing using supervised machine learning on product state data," Journal of Intelligent Manufacturing, vol. 25, no. 5, pp. 1167-1180, 2014.

[2] T. M. Mitchell, "Machine learning," ed: McGraw-hill New York, 1997.

[3] J. G. de Oliveira and D. Dornfeld, "Application of AE contact sensing in reliable grinding monitoring," CIRP Annals, vol. 50, no. 1, pp. 217-220, 2001.

[4] P. K. Prakasam and S. Subbiah, "Analysis of 1D Abrasive Vibratory Finishing Using Acoustic Emission," in ASME 2013 International Manufacturing Science and Engineering Conference collocated with the 41st North American Manufacturing Research Conference, 2013: American Society of Mechanical Engineers Digital Collection.

[5] V. Pandiyan and T. Tjahjowidodo, "Use of Acoustic Emissions to detect change in contact mechanisms caused by tool wear in abrasive belt grinding process," Wear, vol. 436, p. 203047, 2019.

[6] J. V. Abellan-Nebot and F. R. Subirón, "A review of machining monitoring systems based on artificial intelligence process models," The International Journal of Advanced Manufacturing Technology, vol. 47, no. 1-4, pp. 237-257, 2010.

[7] T. Ozel and Y. Karpat, "Prediction of surface roughness and tool wear in finish dry hard turning using back propagation neural networks," in CD-Proceedings of 17th International Conference on Production Research, 2003.

[8] P. Benardos and G.-C. Vosniakos, "Predicting surface roughness in machining: a review," International journal of machine tools and manufacture, vol. 43, no. 8, pp. 833-844, 2003.

[9] S. S. Lee and J. C. Chen, "On-line surface roughness recognition system using artificial neural networks system in turning operations," The International Journal of Advanced Manufacturing Technology, vol. 22, no. 7-8, pp. 498-509, 2003.

[10] M. A. Sellitto, E. Balugani, R. Gamberini, and B. Rimini, "A fuzzy logic control application to the cement industry," IFAC-PapersOnLine, vol. 51, no. 11, pp. 1542-1547, 2018.

[11] M. M. Adnan, A. Sarkheyli, A. M. Zain, and H. Haron, "Fuzzy logic for modeling machining process: a review," Artificial Intelligence Review, vol. 43, no. 3, pp. 345-379, 2015.

[12] F. Čuš and U. Župerl, "Real-time cutting tool condition monitoring in milling," Strojniški vestnikJournal of Mechanical Engineering, vol. 57, no. 2, pp. 142-150, 2011.

[13] V. Vapnik, The nature of statistical learning theory. Springer science \& business media, 2013.

[14] C. Campbell, "Kernel methods: a survey of current techniques," Neurocomputing, vol. 48, no. 1-4, pp. 63-84, 2002.

[15] D. Shi and N. N. Gindy, "Tool wear predictive model based on least squares support vector machines," Mechanical Systems and Signal Processing, vol. 21, no. 4, pp. 1799-1814, 2007.

[16] D. Brezak, D. Majetic, T. Udiljak, and J. Kasac, "Tool wear estimation using an analytic fuzzy classifier and support vector machines," Journal of Intelligent Manufacturing, vol. 23, no. 3, pp. 797 809, 2012.

[17] V. Pandiyan, W. Caesarendra, A. Glowacz, and T. Tjahjowidodo, "Modelling of Material Removal in Abrasive Belt Grinding Process: A Regression Approach," Symmetry, vol. 12, no. 1, p. 99, 2020.

[18] L. Breiman, "Random forests," Machine learning, vol. 45, no. 1, pp. 5-32, 2001.

[19] Y. LeCun, "Generalization and network design strategies. Connectionism in Perspective," Zurich, Switzerland, Elsiever, 1989.

[20] Y. LeCun, Y. Bengio, and G. Hinton, "Deep learning. nature 521," 2015.

[21] C. Thornton, F. Hutter, H. H. Hoos, and K. Leyton-Brown, "Auto-WEKA: Combined selection and hyperparameter optimization of classification algorithms," in Proceedings of the 19th ACM SIGKDD international conference on Knowledge discovery and data mining, 2013: ACM, pp. 847-855.

[22] Y. LeCun and Y. Bengio, "Convolutional networks for images, speech, and time series," The handbook of brain theory and neural networks, vol. 3361, no. 10, p. 1995, 1995. 
[23] X.-C. Cao, B.-Q. Chen, B. Yao, and W.-P. He, "Combining translation-invariant wavelet frames and convolutional neural network for intelligent tool wear state identification," Computers in Industry, vol. 106, pp. 71-84, 2019/04/01/ 2019, doi: https://doi.org/10.1016/j.compind.2018.12.018.

[24] W.-J. Lin, S.-H. Lo, H.-T. Young, and C.-L. Hung, "Evaluation of Deep Learning Neural Networks for Surface Roughness Prediction Using Vibration Signal Analysis," Applied Sciences, vol. 9, no. 7, p. 1462, 2019. [Online]. Available: http://www.mdpi.com/2076-3417/9/7/1462.

[25] L. M. Owsley, L. E. Atlas, and G. D. Bernard, "Self-organizing feature maps and hidden Markov models for machine-tool monitoring," IEEE Transactions on Signal Processing, vol. 45, no. 11, pp. 2787-2798, 1997.

[26] L. Heck and J. McClellan, "Mechanical system monitoring using hidden Markov models," in [Proceedings] ICASSP 91: 1991 International Conference on Acoustics, Speech, and Signal Processing, 1991: IEEE, pp. 1697-1700.

[27] G. Vetrichelvan, S. Sundaram, S. S. Kumaran, and P. Velmurugan, "An investigation of tool wear using acoustic emission and genetic algorithm," Journal of Vibration and Control, vol. 21, no. 15, pp. 3061-3066, 2015.

[28] R. Q. Sardinas, M. R. Santana, and E. A. Brindis, "Genetic algorithm-based multi-objective optimization of cutting parameters in turning processes," Engineering Applications of Artificial Intelligence, vol. 19, no. 2, pp. 127-133, 2006.

[29] J. Karandikar, T. McLeay, S. Turner, and T. Schmitz, "Tool wear monitoring using naive Bayes classifiers," The International Journal of Advanced Manufacturing Technology, vol. 77, no. 9-12, pp. 1613-1626, 2015.

[30] M. Elangovan, K. Ramachandran, and V. Sugumaran, "Studies on Bayes classifier for condition monitoring of single point carbide tipped tool based on statistical and histogram features," Expert Systems with Applications, vol. 37, no. 3, pp. 2059-2065, 2010.

[31] Y. Fu, Y. Zhang, H. Qiao, D. Li, H. Zhou, and J. Leopold, "Analysis of Feature Extracting Ability for Cutting State Monitoring Using Deep Belief Networks," Procedia CIRP, vol. 31, pp. 29-34, 2015/01/01/ 2015, doi: https://doi.org/10.1016/i.procir.2015.03.016.

[32] A. Gouarir, G. Martínez-Arellano, G. Terrazas, P. Benardos, and S. Ratchev, "In-process Tool Wear Prediction System Based on Machine Learning Techniques and Force Analysis," Procedia CIRP, vol. 77, pp. 501-504, 2018/01/01/ 2018, doi: https://doi.org/10.1016/i.procir.2018.08.253.

[33] S. A. Shevchik, C. Kenel, C. Leinenbach, and K. Wasmer, "Acoustic emission for in situ quality monitoring in additive manufacturing using spectral convolutional neural networks," Additive Manufacturing, vol. 21, pp. 598-604, 2018/05/01/ 2018, doi: https://doi.org/10.1016/j.addma.2017.11.012.

[34] S. Kalpakjian and S. Schmid, "Manufacturing engineering and technology. Sekar, KV ed," ed: Prentice Hall, Pearson Education South Asia Pte Ltd., Singapore, 2014.

[35] J. F. G. d. Oliveira, E. J. d. Silva, C. Guo, and F. Hashimoto, "Industrial challenges in grinding," CIRP annals, vol. 58, no. 2, pp. 663-680, 2009.

[36] M. J. Jackson and J. P. Davim, Machining with abrasives. Springer, 2011.

[37] I. Inasaki, H. K. Tönshoff, and T. D. Howes, "Abrasive Machining in the Future," CIRP Annals, vol. 42, no. 2, pp. 723-732, 1993/01/01/ 1993, doi: https://doi.org/10.1016/S0007-8506(07)62535-9.

[38] P. Seyfried, H. Kunzmann, P. McKeown, and M. Weck, Progress in Precision Engineering. [electronic resource] : Proceedings of the 6th International Precision Engineering Seminar (IPES 6)/2nd International Conference on Ultraprecision in Manufacturing Engineering (UME 2), May, 1991 Braunschweig, Germany. Berlin, Heidelberg : Springer Berlin Heidelberg, 1991., 1991.

[39] W. R. DeVries, Analysis of material removal processes. Springer Science \& Business Media, 1991.

[40] H. Nakazawa, Principles of precision engineering. Oxford University Press, USA, 1994.

[41] I. D. Marinescu, W. B. Rowe, B. Dimitrov, and H. Ohmori, "9 - Abrasives and abrasive tools," in Tribology of Abrasive Machining Processes (Second Edition), I. D. Marinescu, W. B. Rowe, B. Dimitrov, and H. Ohmori Eds. Oxford: William Andrew Publishing, 2013, pp. 243-311. 
[42] J. F. G. Oliveira, E. J. Silva, C. Guo, and F. Hashimoto, "Industrial challenges in grinding," CIRP Annals - Manufacturing Technology, vol. 58, no. 2, pp. 663-680, 2009, doi: 10.1016/j.cirp.2009.09.006.

[43] M. Moore, "A review of two-body abrasive wear," Wear, vol. 27, no. 1, pp. 1-17, 1974.

[44] S. Kalpakjian, Manufacturing processes for engineering materials. Pearson Education India, 1984.

[45] V. Pandiyan and T. Tjahjowidodo, "Use of Acoustic Emissions to detect change in contact mechanisms caused by tool wear in abrasive belt grinding process," Wear, vol. 436-437, p. 203047, 2019/10/15/ 2019, doi: https://doi.org/10.1016/j.wear.2019.203047.

[46] S. K. Dean and E. D. Doyle, "Significance of grit morphology in fine abrasion," Wear, vol. 35, no. 1, pp. 123-129, 1975/11/01/ 1975, doi: https://doi.org/10.1016/0043-1648(75)90147-7.

[47] S. Malkin and C. Guo, Grinding technology: theory and application of machining with abrasives. Industrial Press Inc., 2008.

[48] K. H. Z. Gahr, "Formation of wear debris by the abrasion of ductile metals," Wear, vol. 74, no. 2, pp. 353-373, 1981/12/22/ 1981, doi: https://doi.org/10.1016/0043-1648(81)90173-3.

[49] J. Griffin, "Pattern recognition of micro and macro grinding phenomenon with a generic strategy to machine process monitoring," University of Nottingham, 2008.

[50] Z. B. Hou and R. Komanduri, "On the mechanics of the grinding process - Part I. Stochastic nature of the grinding process," International Journal of Machine Tools and Manufacture, vol. 43, no. 15, pp. 1579-1593, 12// 2003, doi: https://doi.org/10.1016/S0890-6955(03)00186-X.

[51] S. Mezghani, M. El Mansori, and E. Sura, "Wear mechanism maps for the belt finishing of steel and cast iron," Wear, vol. 267, no. 1-4, pp. 86-91, 6/15/ 2009, doi: https://doi.org/10.1016/j.wear.2008.12.113.

[52] W. B. Rowe, Principles of modern grinding technology. William Andrew, 2013.

[53] T. Kayaba, K. Hokkirigawa, and K. Kato, "Analysis of the abrasive wear mechanism by successive observations of wear processes in a scanning electron microscope," Wear, vol. 110, no. 3-4, pp. 419430, 1986.

[54] K. H. Z. Gahr, "Modelling of two-body abrasive wear," Wear, vol. 124, no. 1, pp. 87-103, 1988/05/16/ 1988, doi: https://doi.org/10.1016/0043-1648(88)90236-0.

[55] R. Azouzi and M. Guillot, "On-line prediction of surface finish and dimensional deviation in turning using neural network based sensor fusion," International Journal of Machine Tools and Manufacture, vol. 37, no. 9, pp. 1201-1217, 1997/09/01/ 1997, doi: https://doi.org/10.1016/S0890-6955(97)00013-8.

[56] J. Kopac and P. Krajnik, "High-performance grinding-a review," Journal of Materials Processing Technology, vol. 175, no. 1-3, pp. 278-284, 2006.

[57] V. P. Astakhov, "Surface Integrity - Definition and Importance in Functional Performance," in Surface Integrity in Machining, J. P. Davim Ed. London: Springer London, 2010, pp. 1-35.

[58] C. Wu, J. Pang, B. Li, and S. Y. Liang, "High-speed grinding of HIP-SiC ceramics on transformation of microscopic features," The International Journal of Advanced Manufacturing Technology, vol. 102, no. 5-8, pp. 1913-1921, 2019.

[59] Z. Ding, G. Sun, M. Guo, X. Jiang, B. Li, and S. Y. Liang, "Effect of phase transition on microgrinding-induced residual stress," Journal of Materials Processing Technology, vol. 281, p. 116647, 2020.

[60] J. Rech, G. Kermouche, W. Grzesik, C. García-Rosales, A. Khellouki, and V. García-Navas, "Characterization and modelling of the residual stresses induced by belt finishing on a AISI52100 hardened steel," Journal of Materials Processing Technology, vol. 208, no. 1, pp. 187-195, 2008/11/21/ 2008, doi: https://doi.org/10.1016/j.jmatprotec.2007.12.133.

[61] F. Hashimoto, Y. B. Guo, and A. W. Warren, "Surface Integrity Difference between Hard Turned and Ground Surfaces and Its Impact on Fatigue Life," CIRP Annals, vol. 55, no. 1, pp. 81-84, 2006/01/01/ 2006, doi: https://doi.org/10.1016/S0007-8506(07)60371-0. 
[62] E. Brinksmeier and T. Brockhoff, "Utilization of Grinding Heat as a New Heat Treatment Process," CIRP Annals, vol. 45, no. 1, pp. 283-286, 1996/01/01/ 1996, doi: https://doi.org/10.1016/S00078506(07)63064-9.

[63] S. Han, F. Salvatore, and J. Rech, "Residual stress profiles induced by abrasive flow machining (AFM) in 15-5PH stainless steel internal channel surfaces," Journal of Materials Processing Technology, vol. 267, pp. 348-358, 2019/05/01/ 2019, doi: https://doi.org/10.1016/j.jmatprotec.2018.12.024.

[64] M. J. Jackson and M. P. Hitchiner, "Abrasive tools and bonding systems," in Machining with abrasives: Springer, 2011, pp. 1-77.

[65] A. P. S. Arunachalam, S. Idapalapati, and S. Subbiah, "Multi-criteria decision making techniques for compliant polishing tool selection," The International Journal of Advanced Manufacturing Technology, vol. 79, no. 1-4, pp. 519-530, 2015.

[66] V. Pandiyan, W. Caesarendra, T. Tjahjowidodo, and G. Praveen, "Predictive modelling and analysis of process parameters on material removal characteristics in abrasive belt grinding process," Applied Sciences, vol. 7, no. 4, p. 363, 2017.

[67] C.-X. Feng, X. Wang, and Z. Yu, "Neural networks modeling of honing surface roughness parameters defined by ISO 13565," Journal of manufacturing systems, vol. 21, no. 5, pp. 395-408, 2002.

[68] I. Inasaki, B. Karpuschewski, and H. S. Lee, "Grinding Chatter - Origin and Suppression," CIRP Annals, vol. 50, no. 2, pp. 515-534, 2001/01/01/ 2001, doi: https://doi.org/10.1016/S0007$\underline{8506(07) 62992-8 .}$.

[69] J. Gradišek, A. Baus, E. Govekar, F. Klocke, and I. Grabec, "Automatic chatter detection in grinding," International Journal of Machine Tools and Manufacture, vol. 43, no. 14, pp. 1397-1403, 2003/11/01/ 2003, doi: https://doi.org/10.1016/S0890-6955(03)00184-6.

[70] K. Wegener, H. W. Hoffmeister, B. Karpuschewski, F. Kuster, W. C. Hahmann, and M. Rabiey, "Conditioning and monitoring of grinding wheels," CIRP Annals, vol. 60, no. 2, pp. 757-777, 2011/01/01/ 2011, doi: https://doi.org/10.1016/j.cirp.2011.05.003.

[71] H. Tönshoff, M. Jung, S. Männel, and W. Rietz, "Using acoustic emission signals for monitoring of production processes," Ultrasonics, vol. 37, no. 10, pp. 681-686, 2000.

[72] B. Linke, Life cycle and sustainability of abrasive tools. Springer, 2016.

[73] K. Wegener, H.-W. Hoffmeister, B. Karpuschewski, F. Kuster, W.-C. Hahmann, and M. Rabiey, "Conditioning and monitoring of grinding wheels," CIRP annals, vol. 60, no. 2, pp. 757-777, 2011.

[74] V. Pandiyan, "Modelling and in-process monitoring of abrasive belt grinding process," 2019.

[75] V. Pandiyan, W. Caesarendra, T. Tjahjowidodo, and H. H. Tan, "In-process tool condition monitoring in compliant abrasive belt grinding process using support vector machine and genetic algorithm," Journal of Manufacturing Processes, vol. 31, pp. 199-213, 2018/01/01/ 2018, doi: https://doi.org/10.1016/i.jmapro.2017.11.014.

[76] A. Fletcher, J. Hull, J. Mackie, and S. Trengove, "Computer modelling of the abrasive flow machining process," in Surface Engineering: Springer, 1990, pp. 592-601.

[77] K. Przyklenek, "Abrasive Flow Machining: a Process for Surface Finishing and Deburring of Workpieces With a Complicated Shape," Advances in Surface Treatments. Technology--Applications-Effects., vol. 5, pp. 123-138, 1986.

[78] R. Williams, "Acoustic emission characteristics of abrasive flow machining," Journal of manufacturing science and engineering, vol. 120, no. 2, pp. 264-271, 1998.

[79] M. Buijs and K. K.-v. Houten, "Three-body abrasion of brittle materials as studied by lapping," Wear, vol. 166, no. 2, pp. 237-245, 1993/07/01/ 1993, doi: https://doi.org/10.1016/0043-1648(93)90267-P.

[80] T. Kasai, K. Horio, and A. Kobayashi, "Improvement of Conventional Polishing Conditions for Obtaining Super Smooth Surfaces of Glass and Metal Works," CIRP Annals, vol. 39, no. 1, pp. 321 324, 1990/01/01/ 1990, doi: https://doi.org/10.1016/S0007-8506(07)61063-4.

[81] E. Holzknecht, "Everything you need to know about mechanical/mass finishing: A workshop on the role of media in mechanical surface finishing," Metal Finishing, vol. 107, no. 5, pp. 27-31, 2009/05/01/ 2009, doi: https://doi.org/10.1016/S0026-0576(09)80098-6. 
[82] H. K. Tönshoff, T. Friemuth, and J. C. Becker, "Process Monitoring in Grinding," CIRP Annals, vol. 51, no. 2, pp. 551-571, 2002/01/01/ 2002, doi: https://doi.org/10.1016/S0007-8506(07)61700-4.

[83] R. C. Luo and M. G. Kay, "A tutorial on multisensor integration and fusion," in [Proceedings] IECON'90: 16th Annual Conference of IEEE Industrial Electronics Society, 1990: IEEE, pp. 707-722.

[84] R. Teti and S. Kumara, "Intelligent computing methods for manufacturing systems," Cirp Annals, vol. 46, no. 2, pp. 629-652, 1997.

[85] D. Dornfeld A, "In process recognition of cutting states," JSME international journal. Ser. C, Dynamics, control, robotics, design and manufacturing, vol. 37, no. 4, pp. 638-650, 1994.

[86] J. Abdul, "The Shannon Sampling Theorem-1ts Various Extensions and Applications: A," Proceedings of the IEEE, vol. 65, no. 11, p. 1565, 1977.

[87] R. E. Williams, "Acoustic Emission Characteristics of Abrasive Flow Machining," Journal of Manufacturing Science and Engineering, vol. 120, no. 2, pp. 264-271, 1998, doi: 10.1115/1.2830123.

[88] J. M. Crichigno Filho, C. R. Teixeira, and L. V. O. D. Valentina, "An investigation of acoustic emission to monitoring flat lapping with non-replenished slurry," The International Journal of Advanced Manufacturing Technology, vol. 33, no. 7, pp. 730-737, 2007/07/01 2007, doi: 10.1007/s00170-006-0504-8.

[89] Y. P. Chang, M. Hashimura, and D. A. Dornfeld, "An Investigation of the AE Signals in the Lapping Process," CIRP Annals, vol. 45, no. 1, pp. 331-334, 1996/01/01/ 1996, doi: https://doi.org/10.1016/S0007-8506(07)63074-1.

[90] P. K. Prakasam and S. Subbiah, "Analysis of 1D Abrasive Vibratory Finishing Using Acoustic Emission," in ASME 2013 International Manufacturing Science and Engineering Conference collocated with the 41st North American Manufacturing Research Conference, 2013: American Society of Mechanical Engineers, pp. V001T01A046-V001T01A046.

[91] J. Chen, H. Chen, J. Xu, J. Wang, X. Zhang, and X. Chen, "Acoustic signal-based tool condition monitoring in belt grinding of nickel-based superalloys using RF classifier and MLR algorithm," The International Journal of Advanced Manufacturing Technology, vol. 98, no. 1-4, pp. 859-872, 2018.

[92] T. Segreto and R. Teti, "Machine learning for in-process end-point detection in robot-assisted polishing using multiple sensor monitoring," The International Journal of Advanced Manufacturing Technology, 2019/05/19 2019, doi: 10.1007/s00170-019-03851-7.

[93] J. H. Ahn, M. C. Lee, H. D. Jeong, S. R. Kim, and K. K. Cho, "Intelligently automated polishing for high quality surface formation of sculptured die," Journal of Materials Processing Technology, vol. 130-131, pp. 339-344, 2002/12/20/ 2002, doi: https://doi.org/10.1016/S0924-0136(02)00821-X.

[94] J. Oliveira and C. Valente, "Fast grinding process control with AE modulated power signals," CIRP Annals, vol. 53, no. 1, pp. 267-270, 2004.

[95] P. Lezanski, "An intelligent system for grinding wheel condition monitoring," Journal of Materials Processing Technology, vol. 109, no. 3, pp. 258-263, 2001.

[96] P. Lezanski, J. Rafalowicz, and J. Jedrzejewski, "An intelligent monitoring system for cylindrical grinding," CIRP annals, vol. 42, no. 1, pp. 393-396, 1993.

[97] I. Inasaki and K. Okamura, "Monitoring of dressing and grinding processes with acoustic emission signals," CIRP Annals, vol. 34, no. 1, pp. 277-280, 1985.

[98] J. F. G. de Oliveira and D. A. Dornfeld, "Dimensional characterization of grinding wheel surface through acoustic emission," CIRP annals, vol. 43, no. 1, pp. 291-294, 1994.

[99] J. Webster, W. Dong, and R. Lindsay, "Raw acoustic emission signal analysis of grinding process," CIRP annals, vol. 45, no. 1, pp. 335-340, 1996.

[100] A. Hassui, A. E. Diniz, J. F. G. Oliveira, J. Felipe, and J. J. F. Gomes, "Experimental evaluation on grinding wheel wear through vibration and acoustic emission," Wear, vol. 217, no. 1, pp. 7-14, 1998/04/15/ 1998, doi: https://doi.org/10.1016/S0043-1648(98)00166-5.

[101] M. Ahrens, R. Fischer, M. Dagen, B. Denkena, and T. Ortmaier, "Abrasion Monitoring and Automatic Chatter Detection in Cylindrical Plunge Grinding," Procedia CIRP, vol. 8, pp. 374-378, 2013/01/01/ 2013, doi: $\underline{\text { https://doi.org/10.1016/j.procir.2013.06.119. }}$. 
[102] T. W. Liao, C.-F. Ting, J. Qu, and P. J. Blau, "A wavelet-based methodology for grinding wheel condition monitoring," International Journal of Machine Tools and Manufacture, vol. 47, no. 3-4, pp. 580-592, 2007.

[103] T. Warren Liao, "Feature extraction and selection from acoustic emission signals with an application in grinding wheel condition monitoring," Engineering Applications of Artificial Intelligence, vol. 23, no. 1, pp. 74-84, 2010/02/01/ 2010, doi: https://doi.org/10.1016/j.engappai.2009.09.004.

[104] A. Arun, K. Rameshkumar, D. Unnikrishnan, and A. Sumesh, "Tool Condition Monitoring Of Cylindrical Grinding Process Using Acoustic Emission Sensor," Materials Today: Proceedings, vol. 5, no. 5, Part 2, pp. 11888-11899, 2018/01/01/ 2018, doi: https://doi.org/10.1016/j.matpr.2018.02.162.

[105] P. R. de Aguiar, E. C. Bianchi, and R. C. Canarim, "Monitoring of grinding burn by acoustic emission," in Acoustic Emission: IntechOpen, 2012.

[106] S. Pathare, R. Gao, B. Varghese, C. Guo, and S. Malkin, "A DSP-based telemetric data acquisition system for in-process monitoring of grinding operation," in IMTC/98 Conference Proceedings. IEEE Instrumentation and Measurement Technology Conference. Where Instrumentation is Going (Cat. No. 98CH36222), 1998, vol. 1: IEEE, pp. 191-196.

[107] L. Xue, F. Naghdy, and C. Cook, "Monitoring of wheel dressing operations for precision grinding," in 2002 IEEE International Conference on Industrial Technology, 2002. IEEE ICIT'02., 2002, vol. 2: IEEE, pp. 1296-1299.

[108] M. Wehmeier and I. Inasaki, "Investigation and utilization of the acoustic emission signal for monitoring the dressing process," Proceedings of the Institution of Mechanical Engineers, Part B: Journal of Engineering Manufacture, vol. 216, no. 4, pp. 543-553, 2002.

[109] C. Jiang, H. Li, Y. Mai, and D. Guo, "Material removal monitoring in precision cylindrical plunge grinding using acoustic emission signal," Proceedings of the Institution of Mechanical Engineers, Part C: Journal of Mechanical Engineering Science, vol. 228, no. 4, pp. 715-722, 2014.

[110] F. A. Alexandre et al., "Tool condition monitoring of aluminum oxide grinding wheel using AE and fuzzy model," The International Journal of Advanced Manufacturing Technology, vol. 96, no. 1-4, pp. 67-79, 2018.

[111] X. Han and T. Wu, "Analysis of acoustic emission in precision and high-efficiency grinding technology," The International Journal of Advanced Manufacturing Technology, vol. 67, no. 9-12, pp. 1997-2006, 2013.

[112] P. Sutowski, K. Nadolny, and W. Kaplonek, "Monitoring of cylindrical grinding processes by use of a non-contact AE system," International Journal of Precision Engineering and Manufacturing, vol. 13, no. 10, pp. 1737-1743, 2012/10/01 2012, doi: 10.1007/s12541-012-0228-7.

[113] Z. Yang and Z. Yu, "Grinding wheel wear monitoring based on wavelet analysis and support vector machine," The International Journal of Advanced Manufacturing Technology, vol. 62, no. 1, pp. 107121, 2012/09/01 2012, doi: 10.1007/s00170-011-3797-1.

[114] H. K. Tönshoff, M. Jung, S. Männel, and W. Rietz, "Using acoustic emission signals for monitoring of production processes," Ultrasonics, vol. 37, no. 10, pp. 681-686, 2000/07/01/ 2000, doi: https://doi.org/10.1016/S0041-624X(00)00026-3.

[115] S. Saravanapriyan, L. Vijayaraghavan, and R. Krishnamurthy, "On-line detection of grinding burn by integrated sensing," in SIcon/01. Sensors for Industry Conference. Proceedings of the First ISA/IEEE. Sensors for Industry Conference (Cat. No. 01EX459), 2001: IEEE, pp. 89-94.

[116] E. Susič and I. Grabec, "Characterization of the grinding process by acoustic emission," International Journal of Machine Tools and Manufacture, vol. 40, no. 2, pp. 225-238, 2000.

[117] Q. Liu, X. Chen, and N. Gindy, "Fuzzy pattern recognition of AE signals for grinding burn," International Journal of Machine Tools and Manufacture, vol. 45, no. 7-8, pp. 811-818, 2005.

[118] T. W. Liao, "Feature extraction and selection from acoustic emission signals with an application in grinding wheel condition monitoring," Engineering Applications of Artificial Intelligence, vol. 23, no. 1, pp. 74-84, 2010. 
[119] W. Guo, B. Li, S. Shen, and Q. Zhou, "An intelligent grinding burn detection system based on twostage feature selection and stacked sparse autoencoder," The International Journal of Advanced Manufacturing Technology, pp. 1-11, 2019.

[120] W. Guo, B. Li, and Q. Zhou, "An intelligent monitoring system of grinding wheel wear based on twostage feature selection and Long Short-Term Memory network," Proceedings of the Institution of Mechanical Engineers, Part B: Journal of Engineering Manufacture, vol. 233, no. 13, pp. 2436-2446, 2019, doi: 10.1177/0954405419840556.

[121] W. Guo, B. Li, S. Shen, and Q. Zhou, "An intelligent grinding burn detection system based on twostage feature selection and stacked sparse autoencoder," The International Journal of Advanced Manufacturing Technology, vol. 103, no. 5, pp. 2837-2847, 2019/08/01 2019, doi: 10.1007/s00170019-03748-5.

[122] P. R. de Aguiar, P. Willett, and J. Webster, "Acoustic emission applied to detect workpiece burn during grinding," in Acoustic Emission: Standards and Technology Update: ASTM International, 1999.

[123] Y. Chang and D. Dornfeld, "Chatter and surface pattern detection for cylindrical grinding using a fluid coupled acoustic emission sensor," Machining of Advanced Materials, pp. 159-167, 1993.

[124] H. Eda, "In-process detection of grinding burn by means of utilizing acoustic emission," Bull. Jpn. Soc. Precis. Eng., vol. 18, no. 4, pp. 299-304, 1984.

[125] J. Webster, I. Marinescu, R. Bennett, and R. Lindsay, "Acoustic emission for process control and monitoring of surface integrity during grinding," CIRP annals, vol. 43, no. 1, pp. 299-304, 1994.

[126] D. Dornfeld and H. G. Cai, "An investigation of grinding and wheel loading using acoustic emission," 1984.

[127] Z. Yang, Z. Yu, C. Xie, and Y. Huang, "Application of Hilbert-Huang Transform to acoustic emission signal for burn feature extraction in surface grinding process," Measurement, vol. 47, pp. 14-21, 2014/01/01/ 2014, doi: https://doi.org/10.1016/j.measurement.2013.08.036.

[128] Q. Liu, X. Chen, and N. Gindy, "Investigation of acoustic emission signals under a simulative environment of grinding burn," International Journal of Machine Tools and Manufacture, vol. 46, no. 3, pp. 284-292, 2006/03/01/ 2006, doi: https://doi.org/10.1016/j.ijmachtools.2005.05.017.

[129] N. Subrahmanya and Y. C. Shin, "Automated Sensor Selection and Fusion for Monitoring and Diagnostics of Plunge Grinding," Journal of Manufacturing Science and Engineering, vol. 130, no. 3, 2008, doi: 10.1115/1.2927439.

[130] J. M. Griffin and X. Chen, "Multiple classification of the acoustic emission signals extracted during burn and chatter anomalies using genetic programming," The International Journal of Advanced Manufacturing Technology, vol. 45, no. 11, p. 1152, 2009/04/09 2009, doi: 10.1007/s00170-009-20267.

[131] E. A. Dias, F. B. Pereira, S. L. M. Ribeiro Filho, and L. C. Brandão, "Monitoring of through-feed centreless grinding processes with acoustic emission signals," Measurement, vol. 94, pp. 71-79, 2016/12/01/ 2016, doi: https://doi.org/10.1016/j.measurement.2016.07.075.

[132] A. A. Mokbel and T. M. A. Maksoud, "Monitoring of the condition of diamond grinding wheels using acoustic emission technique," Journal of Materials Processing Technology, vol. 101, no. 1, pp. 292 297, 2000/04/14/ 2000, doi: https://doi.org/10.1016/S0924-0136(00)00433-7.

[133] C. D. G. Euzebio, P. R. Aguiar, H. I. Miranda, and E. C. Bianchi, "Monitoring of grinding burn by fuzzy logic," in ABCM Symposium Series in Mechatronics, 2012, vol. 4, pp. 637-645.

[134] H. Y. Kim, S. R. Kim, J. H. Ahn, and S. H. Kim, "Process monitoring of centerless grinding using acoustic emission," Journal of Materials Processing Technology, vol. 111, no. 1, pp. 273-278, 2001/04/25/ 2001, doi: https://doi.org/10.1016/S0924-0136(01)00533-7.

[135] M. Kanthababu, M. Shunmugam, and M. Singaperumal, "Tool condition monitoring in honing process using acoustic emission signals," International Journal of Automation and Control, vol. 2, no. 1, pp. 99-112, 2008.

[136] M. Kanthababu, M. Shunmugam, and M. Singaperumal, "Multi-sensors-based condition monitoring for honing of cylinder liners," International Journal of Manufacturing Research, vol. 7, no. 4, pp. 376-396, 2012. 
[137] I. Buj-Corral, J. Álvarez-Flórez, and A. Domínguez-Fernández, "Acoustic emission analysis for the detection of appropriate cutting operations in honing processes," Mechanical Systems and Signal Processing, vol. 99, pp. 873-885, 2018/01/15/ 2018, doi: https://doi.org/10.1016/j.ymssp.2017.06.039.

[138] C. Schmitt, S. Klein, and D. Bähre, "An Introduction to the Vibration Analysis for the Precision Honing of Bores," Procedia Manufacturing, vol. 1, pp. 637-643, 2015/01/01/ 2015, doi: https://doi.org/10.1016/j.promfg.2015.09.056.

[139] V. K. Gorana, V. K. Jain, and G. K. Lal, "Experimental investigation into cutting forces and active grain density during abrasive flow machining," International Journal of Machine Tools and Manufacture, vol. 44, no. 2, pp. 201-211, 2004/02/01/ 2004, doi: https://doi.org/10.1016/j.ijmachtools.2003.10.004.

[140] V. Pandiyan and T. Tjahjowidodo, "In-process endpoint detection of weld seam removal in robotic abrasive belt grinding process," The International Journal of Advanced Manufacturing Technology, vol. 93, no. 5, pp. 1699-1714, 2017/11/01 2017, doi: 10.1007/s00170-017-0646-X.

[141] E. Govekar, A. Baus, J. Gradišek, F. Klocke, and I. Grabec, "A new method for chatter detection in grinding," CIRP Annals, vol. 51, no. 1, pp. 267-270, 2002.

[142] Y. Zeng and E. Forssberg, "Application of vibration signal measurement for monitoring grinding parameters," Mechanical Systems and Signal Processing, vol. 8, no. 6, pp. 703-713, 1994/11/01/ 1994, doi: https://doi.org/10.1006/mssp.1994.1050.

[143] J.-S. Kwak and M.-K. Ha, "Detection of dressing time using the grinding force signal based on the discrete wavelet decomposition," The International Journal of Advanced Manufacturing Technology, vol. 23 , no. 1-2, pp. 87-92, 2004.

[144] D. Ciampini, M. Papini, and J. K. Spelt, "Impact velocity measurement of media in a vibratory finisher," Journal of Materials Processing Technology, vol. 183, no. 2, pp. 347-357, 2007/03/23/ 2007, doi: https://doi.org/10.1016/j.jmatprotec.2006.10.024.

[145] W. Caesarendra, T. Wijaya, T. Tjahjowidodo, B. K. Pappachan, A. Wee, and M. I. Roslan, "Adaptive neuro-fuzzy inference system for deburring stage classification and prediction for indirect quality monitoring," Applied Soft Computing, vol. 72, pp. 565-578, 2018.

[146] Y. Zeng and E. Forssberg, "Monitoring grinding parameters by vibration signal measurement-a primary application," Minerals Engineering, vol. 7, no. 4, pp. 495-501, 1994.

[147] İ. Asiltürk, M. Tinkir, H. El Monuayri, and L. Çelik, "An intelligent system approach for surface roughness and vibrations prediction in cylindrical grinding," International Journal of Computer Integrated Manufacturing, vol. 25, no. 8, pp. 750-759, 2012.

[148] L. Fang, J. Zhao, K. Sun, D. Zheng, and D. Ma, "Temperature as sensitive monitor for efficiency of work in abrasive flow machining," Wear, vol. 266, no. 7, pp. 678-687, 2009/03/25/ 2009, doi: https://doi.org/10.1016/j.wear.2008.08.014.

[149] C. Cheng, J. Li, Y. Liu, M. Nie, and W. Wang, "Deep convolutional neural network-based in-process tool condition monitoring in abrasive belt grinding," Computers in Industry, vol. 106, pp. 1-13, 2019.

[150] X. Zhang, H. Chen, J. Xu, X. Song, J. Wang, and X. Chen, "A novel sound-based belt condition monitoring method for robotic grinding using optimally pruned extreme learning machine," Journal of Materials Processing Technology, vol. 260, pp. 9-19, 2018.

[151] Z. Yang and Z. Yu, "Experimental study of burn classification and prediction using indirect method in surface grinding of AISI 1045 steel," The International Journal of Advanced Manufacturing Technology, vol. 68, no. 9, pp. 2439-2449, 2013/10/01 2013, doi: 10.1007/s00170-013-4882-4.

[152] V. Pandiyan, P. Murugan, T. Tjahjowidodo, W. Caesarendra, O. M. Manyar, and D. J. H. Then, "Inprocess virtual verification of weld seam removal in robotic abrasive belt grinding process using deep learning," Robotics and Computer-Integrated Manufacturing, vol. 57, pp. 477-487, 2019/06/01/ 2019, doi: https://doi.org/10.1016/j.rcim.2019.01.006.

[153] J. Böhm, A. Vernes, G. Vorlaufer, and M. Vellekoop, "Online monitoring of a belt grinding process by using a light scattering method," Applied Optics, vol. 49, no. 30, pp. 5891-5898, 2010/10/20 2010, doi: 10.1364/AO.49.005891. 
[154] L. Ren, G. Zhang, Y. Wang, Q. Zhang, F. Wang, and Y. Huang, "A new in-process material removal rate monitoring approach in abrasive belt grinding," The International Journal of Advanced Manufacturing Technology, vol. 104, no. 5-8, pp. 2715-2726, 2019.

[155] E. Fleischhauer, F. Azimi, P. Tkacik, R. Keanini, and B. Mullany, "Application of particle image velocimetry (PIV) to vibrational finishing," Journal of Materials Processing Technology, vol. 229, pp. 322-328, 2016/03/01/ 2016, doi: https://doi.org/10.1016/j.jmatprotec.2015.09.017.

[156] Z. Feng and X. Chen, "Image processing of the grinding wheel surface," The International Journal of Advanced Manufacturing Technology, vol. 32, no. 5, pp. 452-458, 2007/03/01 2007, doi: 10.1007/s00170-005-0357-6.

[157] S. Lachance, R. Bauer, and A. Warkentin, "Application of region growing method to evaluate the surface condition of grinding wheels," International Journal of Machine Tools and Manufacture, vol. 44, no. 7, pp. 823-829, 2004/06/01/ 2004, doi: https://doi.org/10.1016/j.ijmachtools.2004.01.006.

[158] H. Tsuwa, "An investigation of grinding wheel cutting edges," Journal of Engineering for Industry, vol. 86, no. 4, pp. 371-382, 1964.

[159] T. Suto, T. Waida, and T. Sata, "IN-PROCESS MEASUREMENT OF WHEEL SURFACE IN GRINDING OPERATIONS," in Advances in Machine Tool Design and Research 1969, S. A. Tobias and F. Koenigsberger Eds.: Pergamon, 1970, pp. 171-180.

[160] J. F. G. de Oliveira, R. T. Coelho, and C. K. Neto, "DEVELOPMENT OF AN OPTICAL SCANNER TO STUDY WEAR ON THE WORKING SURFACE OF GRINDING WHEELS," Machining Science and Technology, vol. 3, no. 2, pp. 239-253, 1999/01/01 1999, doi: 10.1080/10940349908945692.

[161] A. Besuyen, "The measurement of the grinding wheel wear with the quantimet image analyzing computer," Annals of the CIRP, vol. 19, no. 1, pp. 619-624, 1971.

[162] H. Yasui, Y. Haraki, and M. Sakata, "Development of automatic image processing system for evaluation of wheel surface condition in ultra-smoothness grinding," in Proceedings of the 16th Annual Meeting of American Society for Precision Engineering (Virginia, USA), 2001.

[163] E. Brinksmeier and F. Werner, "Monitoring of grinding wheel wear," CIRP annals, vol. 41, no. 1, pp. 373-376, 1992.

[164] A. Darafon, A. Warkentin, and R. Bauer, "Characterization of grinding wheel topography using a white chromatic sensor," International Journal of Machine Tools and Manufacture, vol. 70, pp. 22-31, 2013.

[165] V. Gopan and K. L. D. Wins, "Quantitative Analysis of Grinding Wheel Loading Using Image Processing," Procedia Technology, vol. 25, pp. 885-891, 2016.

[166] N. Arunachalam and B. Ramamoorthy, "Texture analysis for grinding wheel wear assessment using machine vision," Proceedings of the Institution of Mechanical Engineers, Part B: Journal of Engineering Manufacture, vol. 221, no. 3, pp. 419-430, 2007.

[167] S. Lachance, A. Warkentin, and R. Bauer, "Development of an automated system for measuring grinding wheel wear flats," Journal of Manufacturing Systems, vol. 22, no. 2, pp. 130-135, 2003/01/01/ 2003, doi: https://doi.org/10.1016/S0278-6125(03)90010-0.

[168] D. Lipiński, W. Kacalak, and R. Tomkowski, "Methodology of evaluation of abrasive tool wear with the use of laser scanning microscopy," Scanning: The Journal of Scanning Microscopies, vol. 36, no. 1, pp. 53-63, 2014.

[169] D. A. Dornfeld, Y. Lee, and A. Chang, "Monitoring of Ultraprecision Machining Processes," The International Journal of Advanced Manufacturing Technology, vol. 21, no. 8, pp. 571-578, 2003/06/01 2003, doi: 10.1007/s00170-002-1294-2.

[170] C. XiaoQi, Z. Hao, and D. Wildermuth, "In-process tool monitoring through acoustic emission sensing," Automated Material Processing Group, Automation Technology Division, vol. 1, 2001.

[171] M. Chandrasekaran, M. Muralidhar, C. M. Krishna, and U. S. Dixit, "Application of soft computing techniques in machining performance prediction and optimization: a literature review," The International Journal of Advanced Manufacturing Technology, vol. 46, no. 5, pp. 445-464, 2010/01/01 2010, doi: 10.1007/s00170-009-2104-x. 
[172] K. Wasmer, P. M. Pochon, D. Sage, and J. H. Giovanola, "Parametric experimental study and design of experiment modelling of sapphire grinding," Journal of Cleaner Production, vol. 141, pp. 323-335, 2017/01/10/ 2017, doi: https://doi.org/10.1016/j.jclepro.2016.09.031.

[173] E. Brinksmeier, H. K. TÖnshoff, C. Czenkusch, and C. Heinzel, "Modelling and optimization of grinding processes," Journal of Intelligent Manufacturing, vol. 9, no. 4, pp. 303-314, 1998/08/01 1998, doi: 10.1023/A:1008908724050.

[174] Y. Ali and L. Zhang, "A fuzzy model for predicting burns in surface grinding of steel," International Journal of Machine Tools and Manufacture, vol. 44, no. 5, pp. 563-571, 2004.

[175] R. D. Nathan, L. Vijayaraghavan, and R. Krishnamurthy, "In-process monitoring of grinding burn in the cylindrical grinding of steel," Journal of Materials Processing Technology, vol. 91, no. 1-3, pp. 37 42, 1999.

[176] M. S. Samhouri and B. W. Surgenor, Surface roughness in grinding: on-line prediction with adaptive neuro-fuzzy inference system. Society of Manufacturing Engineers, 2000.

[177] Y. M. Ali and L. C. Zhang, "Surface roughness prediction of ground components using a fuzzy logic approach," Journal of Materials Processing Technology, vol. 89-90, pp. 561-568, 1999/05/19/ 1999, doi: https://doi.org/10.1016/S0924-0136(99)00022-9.

[178] A. K. Nandi and D. K. Pratihar, "Design of a genetic-fuzzy system to predict surface finish and power requirement in grinding," Fuzzy Sets and Systems, vol. 148, no. 3, pp. 487-504, 2004/12/16/ 2004, doi: https://doi.org/10.1016/j.fss.2003.10.001.

[179] A. K. Nandi and M. K. Banerjee, "FBF-NN-based modelling of cylindrical plunge grinding process using a GA," Journal of Materials Processing Technology, vol. 162-163, pp. 655-664, 2005/05/15/ 2005, doi: https://doi.org/10.1016/i.jmatprotec.2005.02.080.

[180] G.-H. Kim, "Evaluation of Pre-estimation Model to the Inprocess Surface Roughness for Grinding Operations," International Journal of Precision Engineering and Manufacturing, vol. 3, no. 4, pp. 2430, 2002.

[181] U. Çaydaş and A. Hascalık, "A study on surface roughness in abrasive waterjet machining process using artificial neural networks and regression analysis method," Journal of materials processing technology, vol. 202, no. 1-3, pp. 574-582, 2008.

[182] S. S. Lam and A. E. Smith, "Process monitoring of abrasive flow machining using a neural network predictive model," in 6th Industrial Engineering Research Conference Proceedings, 1997, pp. 477-482.

[183] K. L. Petri, R. E. Billo, and B. Bidanda, "A neural network process model for abrasive flow machining operations," Journal of Manufacturing Systems, vol. 17, no. 1, pp. 52-64, 1998.

[184] V. Vijayaraghavan and S. Castagne, "Sustainable manufacturing models for mass finishing process," The International Journal of Advanced Manufacturing Technology, vol. 86, no. 1-4, pp. 49-57, 2016.

[185] A. T. Nguyen and D. L. Butler, "Correlation of grinding wheel topography and grinding performance: A study from a viewpoint of three-dimensional surface characterisation," Journal of Materials Processing Technology, vol. 208, no. 1, pp. 14-23, 2008/11/21/ 2008, doi: https://doi.org/10.1016/j.jmatprotec.2007.12.128.

[186] N. Alagumurthi, K. Palaniradja, and V. Soundararajan, "Optimization of grinding process through design of experiment (DOE) - A comparative study," Materials and manufacturing processes, vol. 21, no. 1, pp. 19-21, 2006.

[187] J.-S. Kwak, "Application of Taguchi and response surface methodologies for geometric error in surface grinding process," International Journal of Machine Tools and Manufacture, vol. 45, no. 3, pp. 327 334, 2005/03/01/ 2005, doi: https://doi.org/10.1016/j.ijmachtools.2004.08.007.

[188] N. Alagumurthi, K. Palaniradja, and V. Soundararajan, "Optimisation of process parameters in grinding on different dimensions and perspectives," International Journal of Industrial and Systems Engineering, vol. 3, no. 4, pp. 447-473, 2008.

[189] N. Baskar, R. Saravanan, P. Asokan, and G. Prabhaharan, "Ants colony algorithm approach for multiobjective optimisation of surface grinding operations," The International Journal of Advanced Manufacturing Technology, vol. 23, no. 5, pp. 311-317, 2004/03/01 2004, doi: 10.1007/s00170-0021533-6. 
[190] A. G. Krishna and K. M. Rao, "Multi-objective optimisation of surface grinding operations using scatter search approach," The International Journal of Advanced Manufacturing Technology, vol. 29, no. 5, pp. 475-480, 2006/09/01 2006, doi: 10.1007/BF02729099.

[191] R. Saravanan and M. Sachithanandam, "Genetic Algorithm (GA) for Multivariable Surface Grinding Process Optimisation Using a Multi-objective Function Model," The International Journal of Advanced Manufacturing Technology, vol. 17, no. 5, pp. 330-338, 2001/02/01 2001, doi: $10.1007 / \mathrm{s} 001700170167$.

[192] J. J. Govindhasamy, S. F. McLoone, G. W. Irwin, J. J. French, and R. P. Doyle, "Neural modelling, control and optimisation of an industrial grinding process," Control Engineering Practice, vol. 13, no. 10, pp. 1243-1258, 2005/10/01/ 2005, doi: https://doi.org/10.1016/j.conengprac.2004.11.006.

[193] D. Axinte and N. Gindy, "Assessment of the effectiveness of a spindle power signal for tool condition monitoring in machining processes," International Journal of Production Research, vol. 42, no. 13, pp. 2679-2691, 2004/07/01 2004, doi: 10.1080/00207540410001671642.

[194] Z. Wang, P. Willett, P. R. DeAguiar, and J. Webster, "Neural network detection of grinding burn from acoustic emission," International Journal of Machine Tools and Manufacture, vol. 41, no. 2, pp. 283 $309,2001$.

[195] P. R. de Aguiar, E. C. Bianchi, R. C. Canarim, and W. Sikorski, "Monitoring of grinding burn by acoustic emission," in Acoustic Emission: InTech, 2012, pp. 341-364.

[196] J.-S. Kwak and M.-K. Ha, "Neural network approach for diagnosis of grinding operation by acoustic emission and power signals," Journal of Materials Processing Technology, vol. 147, no. 1, pp. 65-71, 2004.

[197] J.-S. Kwak and J.-B. Song, "Trouble diagnosis of the grinding process by using acoustic emission signals," International Journal of Machine Tools and Manufacture, vol. 41, no. 6, pp. 899-913, 2001.

[198] A. Arun, K. Rameshkumar, D. Unnikrishnan, and A. Sumesh, "Tool condition monitoring of cylindrical grinding process using acoustic emission sensor," Materials Today: Proceedings, vol. 5, no. 5, pp. 11888-11899, 2018

[199] D. F. G. Moia, I. H. Thomazella, P. R. Aguiar, E. C. Bianchi, C. H. R. Martins, and M. Marchi, "Tool condition monitoring of aluminum oxide grinding wheel in dressing operation using acoustic emission and neural networks," Journal of the Brazilian Society of Mechanical Sciences and Engineering, vol. 37, no. 2, pp. 627-640, 2015/03/01 2015, doi: 10.1007/s40430-014-0191-6.

[200] X. Chen and T. Limchimchol, "Monitoring grinding wheel redress-life using support vector machines," International Journal of Automation and Computing, vol. 3, no. 1, pp. 56-62, 2006.

[201] T. W. Liao, F. Tang, J. Qu, and P. Blau, "Grinding wheel condition monitoring with boosted minimum distance classifiers," Mechanical Systems and Signal Processing, vol. 22, no. 1, pp. 217-232, 2008.

[202] T. W. Liao, G. Hua, J. Qu, and P. J. Blau, "Grinding wheel condition monitoring with hidden Markov model-based clustering methods," Machining science and technology, vol. 10, no. 4, pp. 511-538, 2006.

[203] Z. Yang and Z. Yu, "Grinding wheel wear monitoring based on wavelet analysis and support vector machine," The International Journal of Advanced Manufacturing Technology, vol. 62, no. 1-4, pp. $107-$ $121,2012$.

[204] X. Chen, W. Rowe, Y. Li, and B. Mills, "Grinding vibration detection using a neural network," Proceedings of the Institution of Mechanical Engineers, Part B: Journal of Engineering Manufacture, vol. 210, no. 4, pp. 349-352, 1996.

[205] N.-H. Chiu and Y.-Y. Guao, "State classification of CBN grinding with support vector machine," Journal of Materials Processing Technology, vol. 201, no. 1-3, pp. 601-605, 2008.

[206] C. Shao et al., "Feature selection for manufacturing process monitoring using cross-validation," Journal of Manufacturing Systems, vol. 32, no. 4, pp. 550-555, 2013/10/01/ 2013, doi: https://doi.org/10.1016/j.jmsy.2013.05.006.

[207] A. P. Nagalingam and S. Yeo, "Controlled hydrodynamic cavitation erosion with abrasive particles for internal surface modification of additive manufactured components," Wear, vol. 414, pp. 89-100, 2018. 